OPEN ACCESS

Edited by:

Zhijian Cao,

Wuhan University, China

Reviewed by:

Aifeng $L i$,

Ocean University of China, China

Anwar Ullah,

COMSATS Institute of Information

Technology, Pakistan

*Correspondence:

Huahua Yu

yuhuahua@qdio.ac.cn

Pengcheng $\mathrm{Li}$

pcli@qdio.ac.cn

Specialty section:

This article was submitted to Pharmacology of lon Channels and

Channelopathies,

a section of the journal

Frontiers in Pharmacology

Received: 09 October 2021

Accepted: 02 November 2021

Published: 25 November 2021

Citation:

Yu C, Li R, Yin X, Yu H and Li P (2021)

Synergistic Effect of Proteinase Activity

by Purification and Identification of

Toxic Protease From

Nemopilema nomurai.

Front. Pharmacol. 12:791847.

doi: 10.3389/fphar.2021.791847

\section{Synergistic Effect of Proteinase Activity by Purification and Identification of Toxic Protease From Nemopilema nomurai}

\author{
Chunlin $Y u^{1,2}$, Rongfeng $L i^{1,3}$, Xiujing Yin ${ }^{1,2}$, Huahua $Y u^{1,3 *}$ and Pengcheng $L i^{1,3 *}$ \\ ${ }^{1}$ CAS and Shandong Province Key Laboratory of Experimental Marine Biology, Center for Ocean Mega-Science, Institute of \\ Oceanology, Chinese Academy of Sciences, Qingdao, Qingdao, China, ${ }^{2}$ College of Earth and Planetary Sciences, University of \\ Chinese Academy of Sciences, Beijing, China, ${ }^{3}$ Laboratory for Marine Drugs and Bioproducts, Pilot National Laboratory for \\ Marine Science and Technology, Qingdao, China
}

Scyphozoan Nemopilema nomurai envenomation is an unresolved threat to human health in Asian waters. Nemopilema nomurai venom metalloproteinases show important toxicities in skin damage and inflammation, but there is still no purified protein for further studies. In this study, high proteinase activity fractions in tentacle autolysis were isolated by ammonium sulfate precipitation, DEAE Sepharose Fast Flow, and Superdex 75 chromatography successively. Purification was guided by azocasein hydrolysis activity and SDS-PAGE. The final products were analyzed by LC-MS/MS. Four elution peaks purified by Superdex 75 chromatography had multiple protein bands but did not show proteinase activity. These fractions would recover proteinase activity after mixing again. Regulation mechanisms were speculated as binding metalloproteinase regulator or disaggregating metalloproteinase inhibitor by LC-MS/MS analysis. For the first time, a synergistic effect in $N$. nomurai proteinase activity was found in the purification process.

Keywords: jellyfish Nemopilema nomurai, purification, protease, metalloprotease, synergistic effect

\section{INTRODUCTION}

Jellyfish sting is an important health problem for persons engaged in marine activities, and the symptoms of victims range from itch, pain, inflammation, and edema to cutaneous necrosis and even death (Cegolon et al., 2013). Venom from jellyfish Nemopilema nomurai is responsible for the symptoms of jellyfish envenomation. N. nomurai is widely distributed in the Yellow Sea and East China Sea every summer season (Sun et al., 2015a; Sun et al., 2015b). It has been regarded as a synonymy of Stomolophus meleagris in some research literatures (Liumin et al., 2011). In recent decades, blooms of $N$. nomurai have been of frequent occurrence and became more of a threat to humans in Chinese, Japanese, and Korean waters (Kawahara et al., 2006; Liumin et al., 2011; Xu et al., 2013; Yoon et al., 2014; Sun et al., 2015a; Sun et al., 2015b). This makes N. nomurai venom research more necessary and important.

Jellyfish N. nomurai venom is a complex mixture of peptides and proteins (Li et al., 2014) and has a variety of bioactivities such as hemolytic and antioxidant activities (Yu et al., 2005; Li et al., 2012; Li et al., 2013; Yue et al., 2021). According to the proteome and transcriptome analyses, metalloproteinases are main components in $N$. nomurai venom (Li et al., 2014). The crude venom extracted from nematocysts was identified to have significant metalloproteinase activity (Yue et al., 2017b) and played an important role in pro-inflammatory activity, edematogenic effects, 
lethality, and cytotoxicity (Lee et al., 2011; Yue et al., 2017b; Li et al., 2018; Yue et al., 2021). Through chromatography, some N. nomurai toxins were partially purified, such as hemolytic toxin SmTX (Li et al., 2013) and lethal toxin NnLF (Li et al., 2020). Protease in $N$. nomurai venom, isolated and identified by zymogram, was identified to contain many other protein components (Yue et al., 2017a). A purified protease with only one SDS-PAGE band was isolated from $N$. nomurai venom by HiPrep 26/60 Sephacryl S-200 column, which did not match any high similarity protease in LC-MS/MS analysis (Yue et al., 2021).

Several protein toxins were successfully purified from jellyfish venom by chromatography, such as cytotoxin CcTX-1 and antioxidant protein SmP90 (Rottini et al., 1995; Yang et al., 2003; Helmholz et al., 2008; Lassen et al., 2011; Lassen et al., 2012; Li et al., 2012; Horiike et al., 2015). But more toxins from jellyfish were partially purified (Bloom et al., 1998; Chung et al., 2001; Sanchez-Rodriguez et al., 2006; Li et al., 2011; Li et al., 2013; Li et al., 2018; Li et al., 2020). For example, Rastogi et al. (2017) identified a $95 \mathrm{kDa}$ metalloproteinase in a partially purified product of Rhizostoma pulmo (barrel jellyfish) venom. But there are still no single metalloproteinase purified from the jellyfish venom, which limits the analysis of its molecular structure and action mechanism. In addition to the small amount of toxin and instability, synergistic effects of toxins may increase the difficulty of single metalloproteinase purification.

Synergistic effects in snake venom have been demonstrated to occur between different toxins with different patterns owing to the amounts of toxin purification, characterization, and pathological researches (Doley and Kini, 2009; Xiong and Huang, 2018). The synergetic pain activation mechanism of scorpion toxin BmP01 was deeply revealed based on its molecular structure researches (Yang et al., 2017). Metalloproteinases in snake venom showed different interactions to other subunits and components (Doley and Kini, 2009; Xiong and Huang, 2018). However, there is no report on the synergistic effects of jellyfish toxins, and the regulation mechanism of jellyfish venom metalloproteinase has not been revealed.

In the present study, the toxic protease components in $N$. nomurai tentacle tissue autolysis were purified by activity-guided chromatography. Protein components of the final purified products, which showed a synergistic effect of proteinase activity, were identified by LC-MS/MS analysis to explore the possible active components and regulation mechanism. This study may provide references for further research on the NnVMP and therapy of jellyfish stings.

\section{MATERIALS AND METHODS}

\section{Venomous Sample Collection}

The venomous sample used in protease purification was collected from the supernatant of $N$. nomurai tentacle autolysis. $N$. nomurai was collected from the coastal waters of Huangshan Village, in the Yellow Sea, on August 29, 2018. Tentacle tissues were cut off from N. nomurai and immediately transported back to the laboratory in an ice bath. Every package of the samples was a mixture of multiple $N$. nomurai individuals. The tentacle tissues were mixed with $50 \%(\mathrm{v} / \mathrm{v})$ precooled filtered natural seawater and autolyzed at $4^{\circ} \mathrm{C}$ for 3 days. Then, autolysis solutions were centrifuged at $3000 \mathrm{~g}$ for $15 \mathrm{~min}$. The supernatant was collected as venomous samples for protease purification. Protein concentrations were determined using FolinCiocalteu's phenol reagent (Dingguo Changsheng Biotechnology Co. Ltd., Beijing, China) according to the manufacturer's instructions.

\section{Ammonium Sulfate Fractional Precipitation}

Ammonium sulfate fractional precipitation was performed in a $0^{\circ} \mathrm{C}$ chromatography freezer with sustained magnetic stirring. An appropriate amount of solid ammonium sulfate was added in small amounts repeatedly to $1 \mathrm{~L}$ of the venomous samples and stirred overnight in a $0^{\circ} \mathrm{C}$ freezer. Then, the sample solutions were centrifuged at $10000 \mathrm{~g}$, at $4^{\circ} \mathrm{C}$ for $5 \mathrm{~min}$. All of the supernatants were collected for the preparation of protein precipitation in the subsequent ammonium sulfate saturation. The protein precipitation was redissolved in $100 \mathrm{ml}$ PBS $(20 \mathrm{mM}, \mathrm{pH} 7.4)$ and dialyzed in the same PBS solution at $4^{\circ} \mathrm{C}$ for $48 \mathrm{~h}$ by Spectra/ Por CE dialysis tubing, 500-1000 MWCO. Then, the sample solutions were centrifuged at $4^{\circ} \mathrm{C}, 10000 \mathrm{~g}$ for $5 \mathrm{~min}$ and the supernatant collected for further experiment. The ammonium sulfate saturations set in this experiment were $20,30,40,50,60$, 70 , and $80 \%$.

\section{Chromatography Purification}

About $30 \mathrm{mg}$ protein precipitation collected from 80\% ammonium sulfate saturation was used in DEAE Sepharose Fast Flow chromatography. First, the sample solutions were concentrated by Millipore concentrators, 3,000 Da MWCO, at $4^{\circ} \mathrm{C}, 6000 \mathrm{~g}$, and filtered with a $22 \mu \mathrm{m}$ membrane. The protein samples were purified with a Hiprep DEAE FF 16/10 chromatography column (GE Healthcare, Princeton, NJ) that was coupled to a fast protein liquid AKTA pure chromatography system. The proteins were eluted by a discontinuous $\mathrm{NaCl}$ gradient $(0.1-2 \mathrm{M}), 3 \mathrm{ml} / \mathrm{min}$. The equilibration buffer was $20 \mathrm{mM}$ PBS. Elution buffer A was $20 \mathrm{mM}$ PBS with $2 \mathrm{M} \mathrm{NaCl}, \mathrm{pH}$ 7.4. Each elution peak was pooled and concentrated to test SDS-PAGE and metalloprotease activity. The concentrated fraction of $0.2 \mathrm{M} \mathrm{NaCl}$ elution peak was then filtered and submitted to a HiLoad 16/60 Superdex 75 column (GE Healthcare) with elution buffer B $(0.15 \mathrm{M} \mathrm{NaCl}$, $20 \mathrm{mM}$ PBS, pH 7.4), $1 \mathrm{ml} / \mathrm{min}$. Each elution peak was pooled, concentrated, and tested in SDS-PAGE for metalloprotease activity. The whole chromatography system worked in a $4^{\circ} \mathrm{C}$ freezer.

\section{SDS-PAGE}

SDS-PAGE was performed according to Laemmli's method (Laemmli, 1970). Briefly, $20 \mu \mathrm{g}$ of the protein sample mixed with nonreducing $5 \times$ Protein Loading Buffer (Nanjing Jiancheng Bioengineering Institute, Nanjing, China) was incubated for $5 \mathrm{~min}$ at $100^{\circ} \mathrm{C}$ and then loaded into a $12 \%$ SurePAGE precast gel (GenScript, New Jersey, United States). 
Protein samples were separated in Tris-MOPS-SDS running buffer (GenScript, New Jersey, United States) in a Bio-Rad Mini-PROTEAN Tetra System (Bio-Rad, California, United States) at $120 \mathrm{~V}$ for approximately $90 \mathrm{~min}$. Gels were stained with $0.5 \%$ Coomassie brilliant blue R-250 and then photographed and analyzed by a Bio-Rad Gel Doc EZ Imager (Bio-Rad, California, United States). The low molecular standard (Yuanye, Shanghai, China) includes rabbit phosphorylase b, $97.4 \mathrm{kDa}$; bovine serum albumin, $66.2 \mathrm{kDa}$; rabbit actin, $43.0 \mathrm{kDa}$; bovine carbonic anhydrase, $31.0 \mathrm{kDa}$; trypsin inhibitor, $20.1 \mathrm{kDa}$; and hen egg-white lysozyme, $14.4 \mathrm{kDa}$.

\section{Proteinase Activity}

Proteinase activity was detected using azocasein according to a previously reported method (Wang et al., 2004) with minor modifications. Briefly, $12.5 \mu \mathrm{g}$ of protein sample was added to $100 \mu \mathrm{L}$ of $5 \mathrm{mg} / \mathrm{ml}$ azocasein (in $50 \mathrm{mM}$ Tris- $\mathrm{HCl}, 100 \mathrm{mM}$ $\mathrm{NaCl}, 5 \mathrm{mM} \mathrm{CaCl}_{2}, \mathrm{pH} 8.8$ ) in a $1.5 \mathrm{ml}$ centrifuge tube and then incubated at $37^{\circ} \mathrm{C}$ for $90 \mathrm{~min}$. The reaction was stopped by adding $200 \mu \mathrm{L}$ of $5 \%$ trichloroacetic acid at room temperature for $30 \mathrm{~min}$. After centrifugation at $10,000 \mathrm{~g}$ for $20 \mathrm{~min}, 150 \mu \mathrm{L}$ of the supernatant was transferred to a 96 -well plate and mixed with $150 \mu \mathrm{L}$ of $0.5 \mathrm{M} \mathrm{NaOH}$. The absorbance was measured by an Infinite M100 plate reader (Tecan Group Ltd., Männedorf, Switzerland) at $450 \mathrm{~nm}$. The PBS group was set as the negative control. Proteinase activity was shown as $\mathrm{U} / \mathrm{mg}$.

\section{LC-MS/MS Identification and Analysis}

The protein components identification of fractions $\mathrm{C}$ and $\mathrm{D}$ was conducted by LC-MS/MS detection and spectra analysis. Briefly, SDT buffer was added to the protein powder sample. The lysate was sonicated and then boiled for $15 \mathrm{~min}$. After being centrifuged at $14000 \mathrm{~g}$ for $40 \mathrm{~min}$, the supernatant was quantified with the BCA Protein Assay Kit (Bio-Rad, United States). Then, $20 \mu \mathrm{g}$ of proteins from each sample were mixed with $5 \times$ loading buffer and boiled for $5 \mathrm{~min}$. The proteins were separated on $12.5 \%$ SDSPAGE. Protein bands were visualized by Coomassie blue R-250 staining. $50 \mu \mathrm{g}$ of sample was added to UA buffer, and DTT and iodoacetamide were then added to reduce and block the cysteine residues. Then trypsin was added. The mixtures were all incubated at $37^{\circ} \mathrm{C}$ for $16-18 \mathrm{~h}$. Each fraction was injected for nano LC-MS/MS analysis. The peptide mixture was loaded onto a reverse-phase trap column (Thermo Scientific Acclaim PepMap100, $100 \mu \mathrm{m} \times 2 \mathrm{~cm}$, NanoViper C18) connected to the $\mathrm{C} 18$ reversed phase analytical column (Thermo Scientific Easy Column, $10 \mathrm{~cm}$ long, $75 \mu \mathrm{m}$ inner diameter, $3 \mu \mathrm{m}$ resin) in buffer A ( $0.1 \%$ formic acid) and separated with a linear gradient of buffer B ( $84 \%$ acetonitrile and $0.1 \%$ formic acid) at a flow rate of $300 \mathrm{~nL} / \mathrm{min}$ controlled by IntelliFlow technology. LC-MS/MS analysis was performed on a Q Exactive mass spectrometer (Thermo Scientific) that was coupled to Easy-nLC (Proxeon Biosystems, now Thermo Fisher Scientific) for $30 \mathrm{~min}$. The mass spectrometer was operated in the positive ion mode. MS data were acquired using a data-dependent top10 method dynamically choosing the most abundant precursor ions from the survey scan $(300-1,800 \mathrm{~m} / \mathrm{z})$ for $\mathrm{HCD}$ fragmentation.

\section{A}

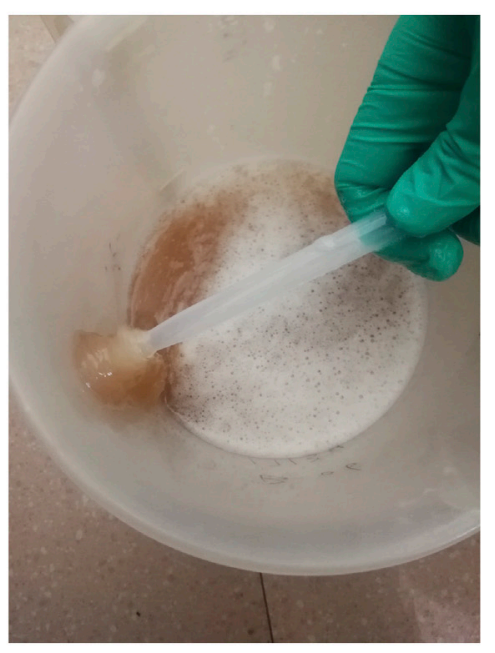

B

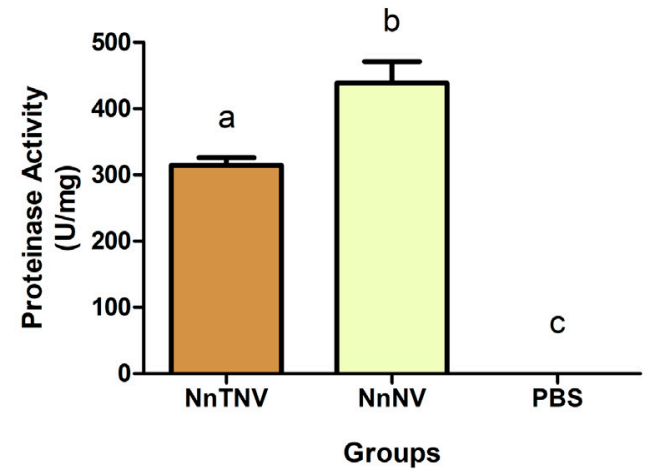

FIGURE 1 | Venomous sample preparation and proteinase activity assay. (A) Fresh Nemopilema nomurai tentacle tissues mixed with 50\% (v/v) filtered natural seawater and completely autolyzed in 3-5 days. Supernatant was used in further experiments. (B) Proteinase activity of venomous samples. NnTNV: Nemopilema nomurai tentacle autolysis; NnNV: Nemopilema nomurai nematocyst venom. Both venomous samples showed significant proteinase activity, $p<0.05$. NnNV was $438.6 \mathrm{U} / \mathrm{mg}$. NnTNV was $314.4 \mathrm{U} / \mathrm{mg}$.

Automatic gain control target was set to $3 \mathrm{e} 6$ and maximum inject time to $10 \mathrm{~ms}$. Dynamic exclusion duration was $40.0 \mathrm{~s}$. Survey scans were acquired at a resolution of 70,000 at m/z 200, and resolution for HCD spectra was set to 17,500 at $\mathrm{m} / \mathrm{z} 200$, and isolation width was $2 \mathrm{~m} / \mathrm{z}$. Normalized collision energy was $30 \mathrm{eV}$, and the underfill ratio, which specifies the minimum percentage of the target value likely to be reached at maximum fill time, was defined as $0.1 \%$. The instrument was run with peptide recognition mode enabled. MS/MS spectra were searched in Tox-Prot (Jungo and Bairoch, 2005) (https://www. UniProt.org/program/Toxins) and $N$. nomurai genome database (Kim et al., 2019) (https://www.ncbi.nlm.nih.gov/genome/? term=Nemopilema+nomurai) with a mass tolerance for precursor ion of $20 \mathrm{ppm}$ and MS/MS tolerance for $0.1 \mathrm{Da}$. Each identified protein should contain at least 1 unique peptide. Only ion scores $>20$ indicate identity or extensive homology $(p<0.05)$. 


\section{Statistical Analysis}

The results were expressed as the mean \pm SEM. The significant differences in the mean between various experimental groups were analyzed by an analysis of variance, followed by Tukey's test. $p<0.05$ was considered statistically significant.

\section{RESULTS}

\section{Isolation of High Proteinase Activity Fractions}

The venomous sample used in the purification process was the supernatant of $N$. nomurai tentacle autolysis (NnTNV, Figure 1A). In Cnidaria, toxins may also exist in other tissues than nematocysts (Zhang et al., 2003; Xiao et al., 2011). In addition, during the tentacle autolysis, some nematocysts were discharged. So, NnTNV contained tentacle and nematocyst samples and showed significant proteinase activity measured as $314 \mathrm{U} / \mathrm{mg}$ (Figure 1B). Moreover, the operation of extracting nematocysts venom, which has been described in a previous research (Li et al., 2011), reduced the protein content by filtration, centrifugation, and ultrasonication. So, NnTNV is more suitable for multistep purification because it has significant activity, more sample volume, and higher protein concentration as shown in Supplementary Table S1.

The first fractionation step, ammonium sulfate fractional precipitation, separated the venomous sample into seven fractions by $20,30,40,50,60,70$, and $80 \%$ saturation. The protein concentration of each fraction is shown in Supplementary Table S2. According to SDS-PAGE, shown in Figure 2A, proteins in NnTNV could be preliminarily separated by solubility. Several proteins, such as the proteins above $97.4 \mathrm{kDa}$ molecular weight in 20 and $30 \%$ saturation and proteins between 31.0 and $43.0 \mathrm{kDa}$ molecular weight in 70 and $80 \%$ saturation were separated effectively. The proteins separated by $20,40,60$, and $80 \%$ saturation showed significant proteinase activity with similar intensity (Figure 2 B). It indicated that there were at least four different proteases contained in NnTNV. The fraction separated by $80 \%$ saturation showed the highest proteinase activity measured as $1,204 \mathrm{U} / \mathrm{mg}$ in mean value and more clear electrophoretic bands than other fractions, so it was selected for the next step. The fractions separated by 30,50 , and $70 \%$ saturation did not show proteinase activity (Figure 2B).

The second fractionation step was DEAE Sepharose Fast Flow chromatography. About $30 \mathrm{mg}$ protein precipitation collected from $80 \%$ ammonium sulfate saturation was used in DEAE Sepharose Fast Flow chromatography. Elution peaks are shown in Figure 3A. The $80 \%$ saturation fraction was separated effectively by different ion intensities. Fractions eluted by 0 and $0.2 \mathrm{M} \mathrm{NaCl}$ contain more proteins judged by the peak shape. Fractions eluted by 0.1 and $0.2 \mathrm{M} \mathrm{NaCl}$ showed more clear electrophoretic bands (Figure 3B). The fraction eluted by $2 \mathrm{M} \mathrm{NaCl}$ did not show clear protein bands. Only the fraction eluted by $0.1 \mathrm{M} \mathrm{NaCl}$ did not show significant proteinase activity. Fractions eluted by 0 and $2 \mathrm{M} \mathrm{NaCl}$ showed similar activity intensity. The fraction eluted by $0.2 \mathrm{M} \mathrm{NaCl}$ showed the

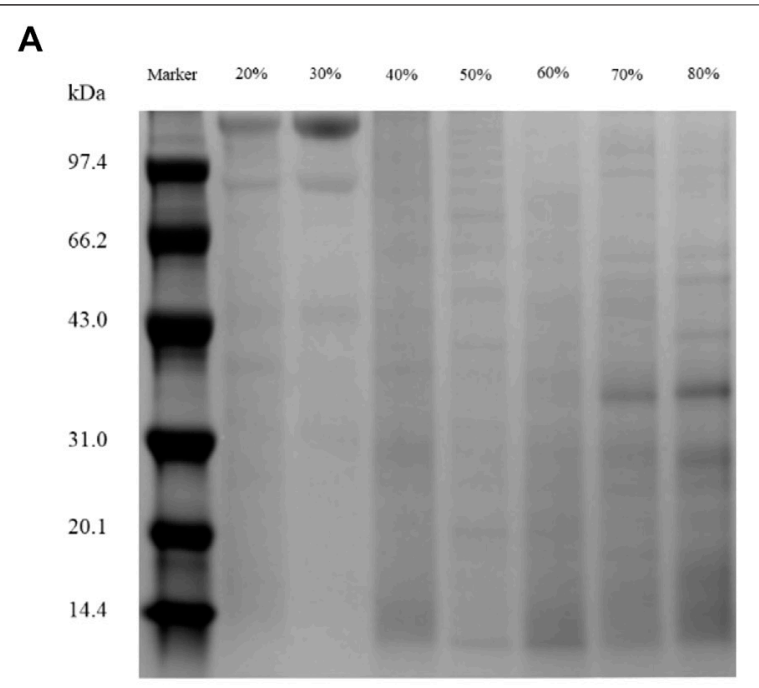

B

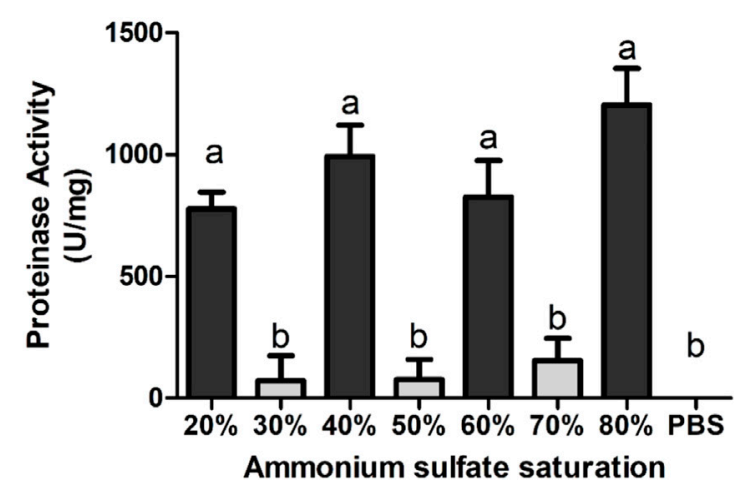

FIGURE 2 | Ammonium sulfate purification of venom from NnTNV. (A) Nonreducing SDS-PAGE of protein fractions in different ammonium sulfate saturations. The number and location of bands of each fraction were obviously different. Bands of fraction $80 \%$ were more clear than others. (B)

Proteinase activity of different protein fractions. Four fractions showed significant proteinase activity, $p<0.05$. Fraction $80 \%$ showed the highest activity.

highest proteinase activity measured as $1065 \mathrm{U} / \mathrm{mg}$, so it was selected for the next step. The protein content of this fraction was about $17.68 \mathrm{mg}$ by calculating the collection volume (Figure 3A) and concentration (Supplementary Table S3). The ion intensity and proteinase activity did not show an obvious relationship (Figure 3C).

The third fractionation step was Superdex chromatography. All collected elution sample of $0.2 \mathrm{M}$ fraction was concentrated, filtered, and submitted onto a HiLoad 16/60 Superdex 75 column. The fraction eluted by $0.2 \mathrm{M} \mathrm{NaCl}$ was separated into four elution peaks as shown in Figure 4A. Elution peaks had mainly separated into peak A-B and peak C-D. Eluent was pooled into fractions A, $\mathrm{B}, \mathrm{C}$, and D. Calculating by collection volume (Figure 4A) and concentration (Supplementary Table S4), the protein content was $0.14 \mathrm{mg}$ in $\mathrm{A}, 1.08 \mathrm{mg}$ in $\mathrm{B}, 1.12 \mathrm{mg}$ in $\mathrm{C}$, and $1.63 \mathrm{mg}$ in $\mathrm{D}$. According to the SDS-PAGE, each fraction showed different electrophoretic bands distribution (Figure 4B). Fractions A and $\mathrm{B}$ had blurry bands above $66.2 \mathrm{kDa}$. Fraction $\mathrm{C}$ had clear 


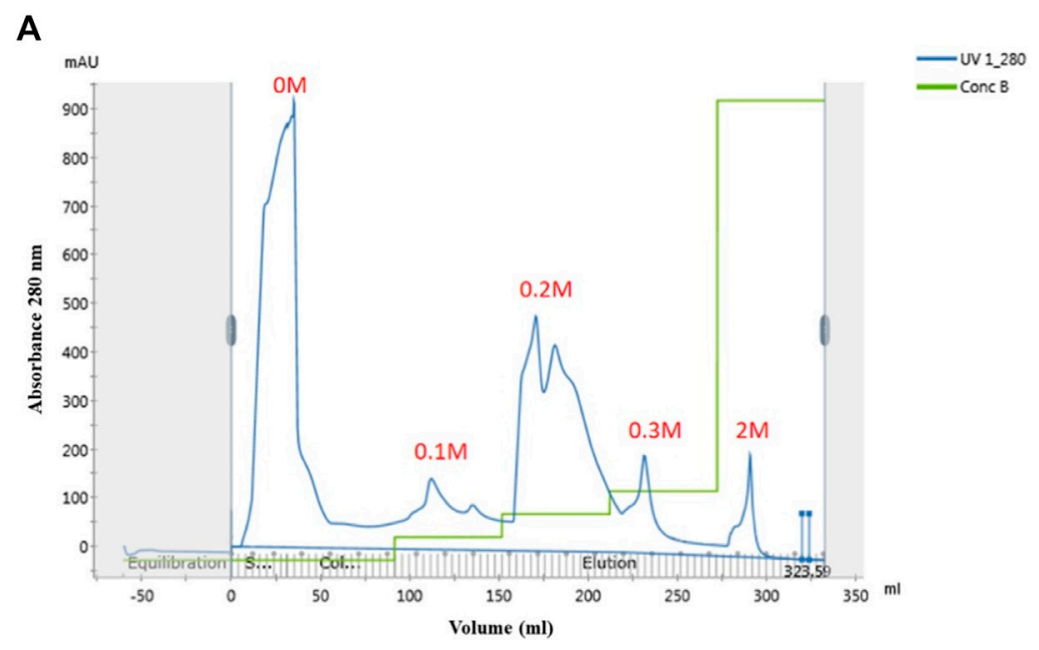

B

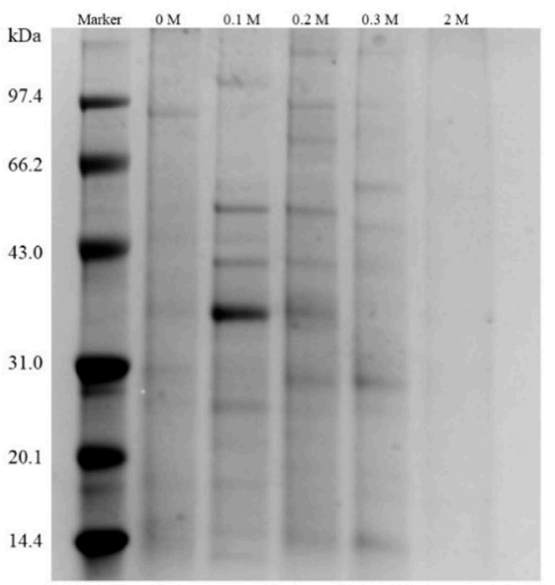

C

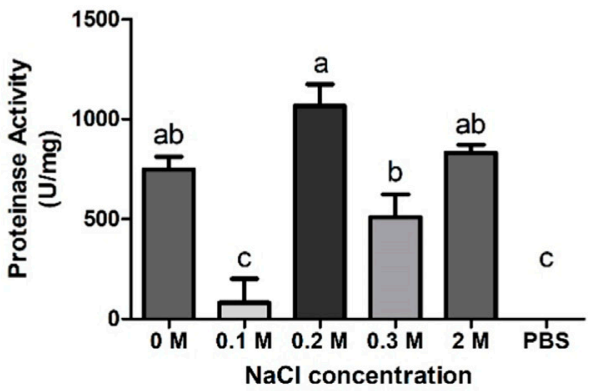

FIGURE 3 |DEAE Sepharose Fast Flow Chromatography purification of protein fraction in $80 \%$ ammonium sulfate saturation. (A) Elution peaks of protein fraction in 80\% ammonium sulfate saturation purified by DEAE Sepharose Fast Flow chromatography. Five independent peaks were obtained. (B) Nonreducing SDS-PAGE of each fraction. Fraction 0.1 and $0.2 \mathrm{M}$ showed more clear protein bands. (C) Proteinase activity of each fraction. Four fractions showed significant proteinase activity, $p<0.05$. Fraction $0.2 \mathrm{M}$ showed the highest activity.

bands between 20.1 and $97.4 \mathrm{kDa}$. Fraction $\mathrm{D}$ had clear bands below $43.0 \mathrm{kDa}$. Fraction $\mathrm{B}$ also had two blurry bands near $20.1 \mathrm{kDa}$. Although the fraction eluted by $0.2 \mathrm{M} \mathrm{NaCl}$ had the highest metalloproteinase activity in all DEAE Sepharose Fast Flow chromatography fractions, its elution peaks further separated by Superdex chromatography did not show significant proteinase activity to the negative control (PBS, 0 $\mathrm{U} / \mathrm{mg}$ ) as shown in Figures 4C,D.

\section{Recover the Proteinase Activity of Deactivated Fractions}

Deactivated fractions could recover the proteinase activity as shown in Figure 5. Mixture groups were made by mixing each fraction in equal volume and equal concentration. Three elution peak mixtures, "A + B," "C + D," and "A + B + C + D", showed significant activity, measured as $220-270 \mathrm{U} / \mathrm{mg}$, to PBS (0 U/mg).
The proteinase activity of other mixtures, measured as 110-180 U/mg, did not show significant differences both to three active groups and PBS.

\section{LC-MS/MS Identification of Fractions C and $D$}

According to the electrophoretic bands shown in Figure 4B, fractions $\mathrm{C}$ and $\mathrm{D}$ showed more clear bands and more obvious differences. Fractions $\mathrm{A}$ and $\mathrm{B}$ might be aggregated high molecular proteins. So, we selected fractions $\mathrm{C}$ and $\mathrm{D}$ to identify the protein components. The spectra obtained from LC-MS/MS were analyzed by the Tox-Prot database (all animal toxins database) and the $N$. nomurai genome database. The mass spectrometry proteomics data have been deposited to the ProteomeXchange Consortium via the PRIDE partner repository with the data set identifier PXD029333. 
A

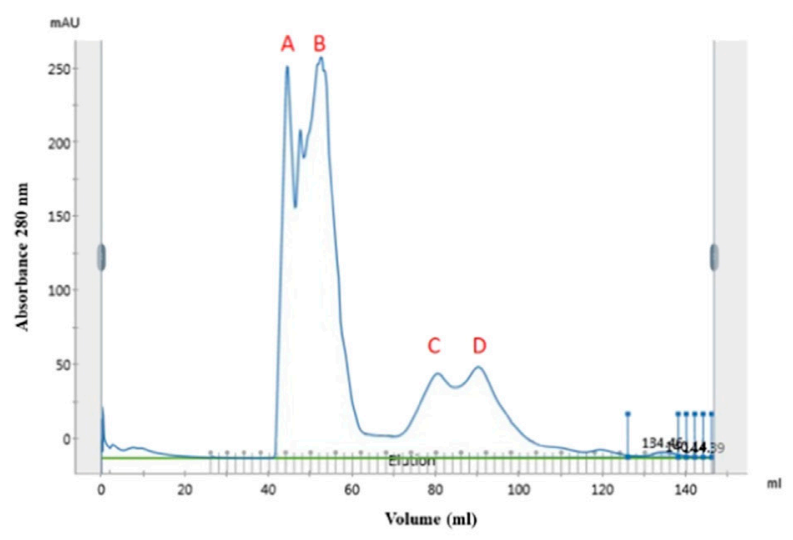

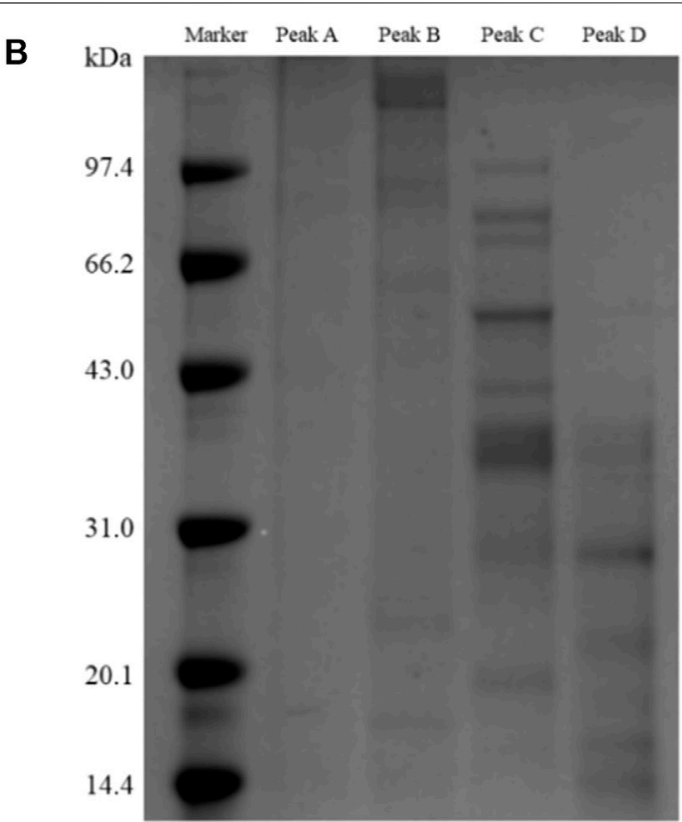

C

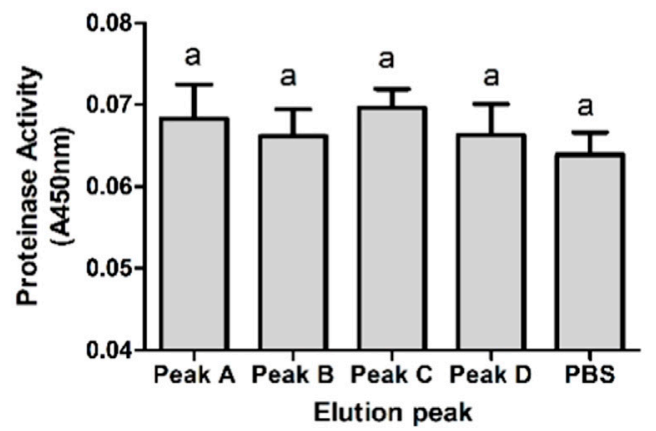

D

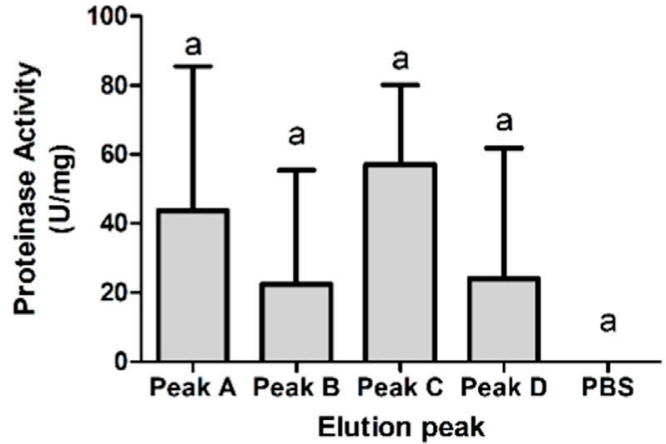

FIGURE 4|Superdex chromatography purification of $0.2 \mathrm{M} \mathrm{NaCl}$-eluted fraction. (A) Elution peaks of $0.2 \mathrm{M} \mathrm{NaCl-eluted} \mathrm{fraction} \mathrm{purified} \mathrm{by} \mathrm{Superdex} \mathrm{75.} \mathrm{Peaks} \mathrm{A}$ and $B$ were well separated from $C$ and D. But components in AB and CD were not entirely separated. (B) Nonreducing SDS-PAGE of each fraction. Protein bands of C and D were similar and more clear than those of A and B. (C,D) Proteinase activity of each fraction showed by A450 nm and U/mg. None of the four fractions showed significant proteinase activity, $p<0.05$.

As seen in Tables 1, 2, the results of the Tox-Prot analysis, a total of 41 peptides in fraction $\mathrm{C}$ were matched to 84 proteins which were classified as 41 protein groups (Table 1), and a total of 35 peptides in fraction $\mathrm{D}$ were matched to 71 proteins which were classified as 34 protein groups (Table 2). Some protein groups contain many high similarity proteins. Dermonecrotic toxin in fraction $\mathrm{D}$ was matched by three different peptides. The matched homologous toxins both in fractions $C$ and $D$ were venom allergen, dermonecrotic toxin, reticulocalbin, peroxiredoxin, serine protease, cysteine-rich venom protein, venom acid phosphatase, L-amino-acid oxidase, ion channel toxin, neurotoxin, etc. Most of these shared groups were matched by the same peptides. Protein toxins only matched in fraction $C$ were phospholipase $A_{1}$, cystatin, zinc metalloproteinase, etc. Protein toxins only matched in fraction $\mathrm{D}$ were snake venom metalloprotease (SVMP) inhibitor, SVMP, hyaluronidase, etc.

The result of $N$. nomurai genome database analysis is shown in Table 3. Only two mitochondrion proteins, ATP synthase F0 subunit 8 and $\mathrm{NADH}$ dehydrogenase subunit $4 \mathrm{~L}$, were matched in fraction $\mathrm{C}$.

\section{DISCUSSION}

As jellyfish stings pose a threat to humans in many marine activities in summer, especially swimming, the study of jellyfish sting mechanism is necessary for therapy researches. N. nomurai is a giant jellyfish widely distributed in the Yellow Sea and East China Sea, which blooms in summer in recent years (Sun 


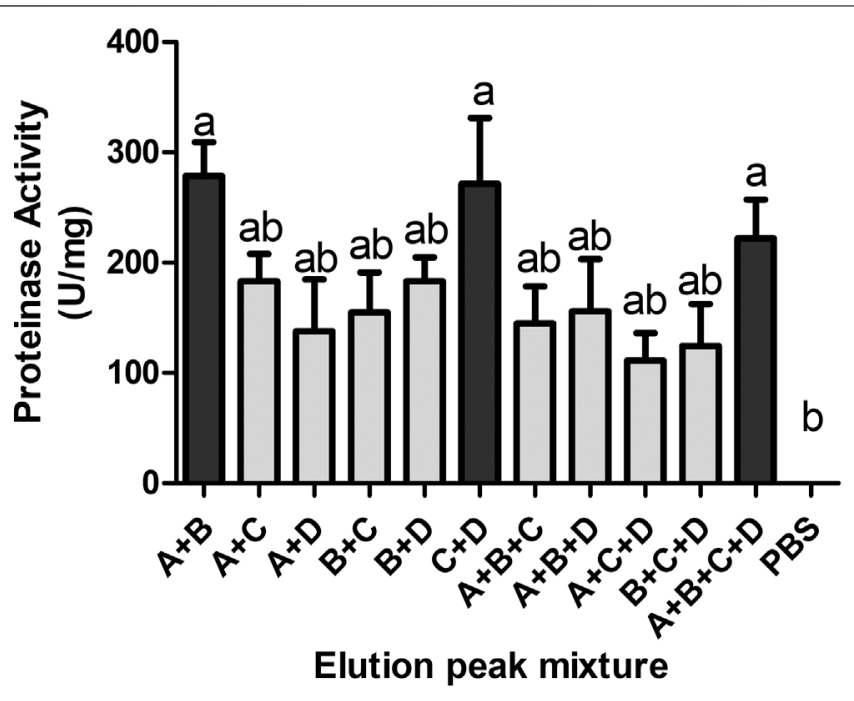

FIGURE 5|Proteinase activity of different mixtures of the four elution peaks. Each group was an equal mixture of elution peaks in the same protein content. Three groups showed significant proteinase activity, $p<0.05$.

et al., 2015a; Sun et al., 2015b). In N. nomurai venom, metalloproteinase is a major component (Li et al., 2014). NnVMPs showed azocasein hydrolysis activity and impacted the expression of many inflammatory factors (Li et al., 2019) and increased vascular permeability by directly degrading basement membrane components (Yue et al., 2021).

Metalloproteinases widely exist in venomous animals, including snakes, scorpions, spiders, jellyfish, etc. and play an important role in digestion and preying. Many different SVMPs are obtained by two or three steps of chromatography, such as CCSV-MPase (Cherifi et al., 2010), Atrase B (Sun and Bao, 2010), BmooMP $\alpha$-II (de Queiroz et al., 2014), and CcD-II (Ami et al., 2017). Additionally, some metalloproteinases can be obtained by cDNA cloning and expression, such as rFIVa (Xu et al., 2006), Ahpfibrase (Zhang et al., 2010), and Jerdonitin (Zhu et al., 2010). Owing to the successful single protein purification, many SVMPs were studied in-depth in structures, functions, and mechanisms. SVMPs can be classified by their domain architecture into type P-I to P-III (Fox and Serrano, 2008). SVMPs are multifunction proteins, and they showed hemorrhagic, procoagulant, anticoagulant, and antiplatelet effects in envenomation cases (Fox and Serrano, 2005). Researches on the jellyfish venom purification are relatively difficult. Only a few toxins were highly purified from jellyfish venom, such as cytotoxin ClGp1, cytotoxin CcTX-1, neurotoxin CcNT, antioxidant protein SmP90 (Rottini et al., 1995; Yang et al., 2003; Helmholz et al., 2008; Lassen et al., 2011; Lassen et al., 2012; Li et al., 2012; Horiike et al., 2015), etc. Techniques most used in venom protein purification were activity-guided multidimensional chromatography, including size-exclude, ion-exchange, reversed-phase, and affinity chromatography. Lassen purified cytotoxin CcTX-1 and neurotoxin CcNT from Cyanea capillata in this program (Lassen et al., 2011; Lassen et al., 2012). Nevertheless, most jellyfish protein toxins could only be partially purified by multi-chromatography, such as a $95 \mathrm{kDa}$ metalloproteinase from R. pulmo (barrel jellyfish) venom (Rastogi et al., 2017) and other hemolytic and lethal jellyfish toxins, such as SmTX from S. meleagris (Li et al., 2013) and NnLF from N. nomurai (Li et al., 2020). Due to the complex composition, it is not easy to get a single toxin component from jellyfish venom. In jellyfish venom, some different protein components have very similar physical properties such as molecule weight. In addition, toxins in jellyfish venom contained different subfamilies and may interact with other components. It was hard to efficiently isolate a single jellyfish toxin protein within two or three chromatography steps. In addition, the protein content in jellyfish nematocyst venom is too small an amount to do repeated chromatography, which makes it difficult to reveal the biological activity of a single toxin component. In this study, proteases from NnTNV were purified by ammonium sulfate precipitation, DEAE Sepharose Fast Flow, and Superdex 75 column chromatography successively. During the purification process, the proteinase activity of $80 \%$ saturation fraction and $0.2 \mathrm{M}$ ion intensity fraction was increased from $314 \mathrm{U} / \mathrm{mg}$ to $1,204 \mathrm{U} / \mathrm{mg}$ and $1,065 \mathrm{U} / \mathrm{mg}$, respectively. But none of the final fractions in Superdex chromatography showed significant proteinase activity to PBS (Figures 4C,D). However, when these fractions were mixed again by the same protein content, the mixed samples " $A+B$, , "C + D," and " $A+B$ $+C+D$ " recovered the activity (Figure 5), which indicated that there was synergistic effect between the final fractions.

Synergistic effect is common in animal venom such as many snake toxins (Doley and Kini, 2009; Xiong and Huang, 2018). Currently, there is no universal method to study the synergistic effects of animal toxins. Laustsen proposed the Toxicity Score method to determine the presence of synergism in venom (Lauridsen et al., 2016). Venom synergistic effect is mainly revealed by the research of venom purification and molecular mechanisms. For example, SVMP may interact with 
TABLE 1 | Toxins of NnTNV purification fraction C identified by LC-MS/MS analysis and Tox-Prot database.

Peptide sequence

AGATNGK

ILKGGLK

VQIVR

KM*LLEK

TLQEK

LNPFR

CLGIR

LICVR

IVEWK.D ! K.IVEWK

AAM ${ }^{\star}$ GTVRAK

$\mathrm{LLM}^{\star} \mathrm{QK}$

EFADK

\begin{tabular}{|c|c|}
\hline & C0JB84 \\
\hline & C0JB83 \\
\hline & COJB76 \\
\hline & C0JB73 \\
\hline & C0JB85 \\
\hline & C0JB80 \\
\hline & COJB79 \\
\hline & C0JB71 \\
\hline & C0JB88 \\
\hline & COJB74 \\
\hline & C0JB86 \\
\hline & C0JB82 \\
\hline & C0JB77 \\
\hline & C0JB69 \\
\hline & C0JB81 \\
\hline & COJB72 \\
\hline & C0JB78 \\
\hline & C0JB75 \\
\hline IELTK & E3P6P2 \\
\hline & E3P6N9 \\
\hline & E3Р6P0 \\
\hline & E3P6N3 \\
\hline & E3P6N8 \\
\hline KTWSGTIIER & F8J2G5 \\
\hline QGYISK & GOLXV8 \\
\hline & P23631 \\
\hline & PODJE3 \\
\hline IWDLK & $\mathrm{H} 1 \mathrm{ZZI8}$ \\
\hline IPILDGDGEATLK & I2C090 \\
\hline LSPEEQQK & J3S9D9 \\
\hline LLDAAK & P0C1Q4 \\
\hline QITMNDLPVGR & P0CV91 \\
\hline ADLDLLR & PODME8 \\
\hline VAACTNEIAGVK & PODPTO \\
\hline EEILR & PODQF3 \\
\hline EQITSRLK & PODSJ9 \\
\hline & PODSJ8 \\
\hline TRTSWDEDIMLIR & P26324 \\
\hline ILIHR & P43445 \\
\hline VSIGIK & P83108 \\
\hline QKNDKK & P86308 \\
\hline ILGGIK & Q2XXP5 \\
\hline ESLEK & Q4JHE2 \\
\hline HM*LDWSGTQK & Q5BLY5 \\
\hline EYLMK & Q5D7H4 \\
\hline ELSIR & Q5Y4X2 \\
\hline
\end{tabular}

Protein ID

Protein name

Toxin To7

Toxin To6

Delta-pseudomyrmecitoxin-Pp1a subunit B

Cysteine-rich venom protein Mr30

U31-theraphotoxin-Cg1a

U31-theraphotoxin-Cg1b

Venom dipeptidyl peptidase 4

Short cationic peptide-6a

Short cationic peptide-6b

Venom serine protease Bi-VSP

Conotoxin Im6.1

M-poneritoxin-Dq4a

M-poneritoxin-Dq4b/U1-poneritoxin-Dq4c/U1-poneritoxin-Dq4d

Potassium channel toxin alpha-KTx 2.19

Potassium channel toxin alpha-KTx 2.14

Phospholipase A1

Probable phospholipase A1 magnifin

Dermonecrotic toxin SdSicTox-betallB1bxiii (Fragment)

Dermonecrotic toxin SaSicTox-betallB1bx (Fragment)

Dermonecrotic toxin SdSicTox-betallB1bix (Fragment)

Dermonecrotic toxin SdSicTox-betallB1ai (Fragment)

Dermonecrotic toxin SdSicTox-betallB1biii (Fragment)

Dermonecrotic toxin SaSicTox-betallB1bxi (Fragment)

Dermonecrotic toxin SaSicTox-betallB1bvi (Fragment)

Dermonecrotic toxin SaSicTox-betallB1ai (Fragment)

Dermonecrotic toxin SaSicTox-betallB1bi (Fragment)

Dermonecrotic toxin SaSicTox-betallB1bxiv (Fragment)

Dermonecrotic toxin SaSicTox-betallB1biv (Fragment)

Dermonecrotic toxin SaSicTox-betallB1bxii (Fragment)

Dermonecrotic toxin SaSicTox-betallB1bviii (Fragment)

Dermonecrotic toxin SaSicTox-betallB1aii (Fragment)

Dermonecrotic toxin SpaSicTox-betallA2 (Fragment)

Dermonecrotic toxin SdSicTox-betallB1bvii (Fragment)

Dermonecrotic toxin SaSicTox-betallB1bii (Fragment)

Dermonecrotic toxin SaSicTox-betallB1aiii (Fragment)

Dermonecrotic toxin SaSicTox-betallB1bv (Fragment)

Cystatin

Cystatin

Cystatin

AsCystatin

Cystatin

Short neurotoxin 342

Alpha-latrotoxin-Lh1a (Fragment)

Alpha-latrotoxin-Lt1a

Alpha-latrotoxin-Lhe1a

Toxin Tpa7

Ophiophagus venom factor

Reticulocalbin-2

Mastoparan-1

Peroxiredoxin-4 (Fragments)

Peptide Hp1239

Phospholipase A1 VesT1.02

U-scoloptoxin(21)-Sm2a

U-myrmeciitoxin(01)-Mg5b

U-myrmeciitoxin(01)-Mg5a

Thrombin-like enzyme ancrod

Short neurotoxin homolog

Neurotoxin

Tachykinin-like peptide-XI

Cysteine-rich venom protein TEL1 (Fragment)

L-amino-acid oxidase

Venom acid phosphatase Acph-1

Inactive hyaluronidase $B$

U2-agatoxin-Ao1n
Cover percent (\%)

8.33

8.24

21.21

1.73

5.22

5.22

0.65

25

26.32

1.39

6.17

21.43

21.43

24.32

24.32

1.64

1.48

1.82

1.82

1.82

1.82

1.82

1.83

1.82

1.82

1.2

1.83

1.82

1.82

1.82

1.82

1.82

1.82

1.82

1.83

1.82

3.55

3.55

3.55

3.55

3.55

12.82

0.44

0.43

0.42

6.10

0.79

2.61

42.86

30.56

10.45

3.99

7.25

13.56

13.56

5.56

6.02

17.14

46.15

2.86

0.97

2.84

1.47

7.14

(Continued on following page) 
TABLE 1 | (Continued) Toxins of NnTNV purification fraction C identified by LC-MS/MS analysis and Tox-Prot database.

\begin{tabular}{|c|c|c|c|}
\hline Peptide sequence & Protein ID & Protein name & Cover percent $(\%)$ \\
\hline VLFDK & Q68Y22 & M-myrmeciitoxin-Mb2a & 5.95 \\
\hline GAEIIR & Q6XLL6 & Potassium channel toxin alpha-KTx 6.9 & 9.84 \\
\hline LPNKDR & Q7SYF1 & Thrombin-like enzyme cerastocytin & 2.34 \\
\hline \multirow[t]{3}{*}{ MELIR } & Q8AY79 & Beta-fibrinogenase stejnefibrase-2 & 1.94 \\
\hline & Q8AY80 & Alpha- and beta-fibrinogenase stejnefibrase- 1 & 1.94 \\
\hline & Q91516 & Venom plasminogen activator TSV-PA & 1.94 \\
\hline \multirow[t]{8}{*}{ KENGRK } & Q8JIR2 & Zinc metalloproteinase/disintegrin-like HR1a & 0.99 \\
\hline & Q10749 & Snake venom metalloproteinase-disintegrin-like mocarhagin & 0.99 \\
\hline & Q4VM08 & Zinc metalloproteinase-disintegrin-like VLAIP-A & 0.97 \\
\hline & Q2UXQ5 & Zinc metalloproteinase-disintegrin-like EoVMP2 & 0.98 \\
\hline & Q2UXR0 & Zinc metalloproteinase-disintegrin-like Eoc1 & 0.98 \\
\hline & B8K1W0 & Zinc metalloproteinase-disintegrin-like daborhagin-K & 0.98 \\
\hline & Q7T046 & Coagulation factor $\mathrm{X}$-activating enzyme heavy chain & 0.98 \\
\hline & Q7LZ61 & Coagulation factor $X$-activating enzyme heavy chain & 0.97 \\
\hline \multirow[t]{2}{*}{ LVPIASK } & Q98956 & Cytotoxin $1 b$ & 8.64 \\
\hline & P86538 & Cytotoxin $2 a$ & 11.67 \\
\hline \multirow[t]{2}{*}{ LLNKR.S ! K.LLNKR } & Q9BPF2 & Conotoxin Vn-05 & 8.20 \\
\hline & Q68IP5 & Conotoxin mr5.4b (Fragment) & 9.26 \\
\hline VATGK & W4VS53 & CRISP/Allergen/PR-1 & 1.23 \\
\hline
\end{tabular}

phospholipase $\mathrm{A}_{2}$ (Xiong et al., 2017). The enzyme activity of P-III metalloproteinase complex was regulated by its subunits (Doley and Kini, 2009). Although there has been no research in jellyfish metalloproteinase synergistic effect, unrevealed interaction of synergistic proteins may impact the bioactivity and purification studies.

As the final fractions were multicomponent, the protein components of fractions $\mathrm{C}$ and D were identified by LC-MS/ MS to reveal the possible mechanism of proteinase activity regulation in $N$. nomurai venom. However, few jellyfish toxins are well understood. A large number of protein toxins were matched in snakes, spiders, scorpions, bees, and other organisms (Table 1, Table 2) by searching in Tox-Prot. The unique peptide count of most matched proteins was only one, but some peptides matched many similar proteins in different organisms, such as peptide KENGRK which was matched to eight different zinc metalloproteinases. It made the peptide sequence more probable to represent the matched protein group. This means even the unique peptide count and cover percent were not high, these matched toxins from other organisms also provided very important references. Similar to the chromatography and SDS-PAGE results, toxins matched in fractions $\mathrm{C}$ and $\mathrm{D}$ showing shared and different components. These different toxins contained in fractions $C$ and $D$ might contain the regulator of proteinase activity, such as phospholipase A1, P-III metalloproteinase, P-I metalloproteinase, and metalloproteinase inhibitor.

In fraction $\mathrm{C}$, the matched toxin proteins which related to proteinase activity were zinc metalloproteinase and serine protease. The peptide sequence matched to zinc metalloproteinase was KENGRK. It matched eight similar P-III metalloproteinases from different snakes. They can produce proteolytic activity and hemorrhage activity (Howes et al., 2003; Morine et al., 2008). This kind of metalloproteinase has metalloproteinase domain, disintegrin domain, and cysteine-rich domain (Gowda et al., 1994; Siigur et al., 2001; Siigur et al., 2004; Trummal et al., 2005; Takeda et al., 2007; Chen et al., 2008). Sequence KENGRK is located in the cysteine-rich domain. The peptide sequences matched to serine protease were CLGIR, TRTSWDEDIMLIR, and LPNKDR. CLGIR matched venom serine protease Bi-VSP from Bombus ignitus (bumblebee). TRTSWDEDIMLIR matched thrombin-like enzyme ancrod from Calloselasma rhodostoma (Malayan pit viper). LPNKDR matched thrombin-like enzyme cerastocytin from Cerastes cerastes (horned desert viper). These serine proteases have fibrinogenolytic activity (Marrakchi et al., 1995; Marrakchi et al., 1997; Dekhil et al., 2003; Choo et al., 2010; Choo et al., 2012).

In fraction $\mathrm{D}$, the matched toxin proteins which related to proteinase activity were SVMP, SVMP inhibitor, and serine protease. Serine protease was matched by peptide sequence TRTSWDEDIMLIR which was also identified in fraction C. The sequence LENVEKEDGGPK was matched to SVMP from Crotalus molossus molossus (Northern black-tailed rattlesnake). This kind of P-I metalloproteinase impairs hemostasis in the envenomed animal (Gutierrez et al., 1995; Farsky et al., 2000; Patino et al., 2010; Bernardes et al., 2013). The sequence QASQKWGR was matched to SVMP inhibitor 02D01 from Echis ocellatus (ocellated saw-scaled viper). This protein may inhibit metalloproteinase activity in the venom gland through abundant pEKW and poly-His-poly-Gly peptides. The inhibition may be disengaged by dilution or physiochemical change (Wagstaff et al., 2008).

These SVMP-like proteins in fractions C and D might be the important factors in regulating azocasein hydrolysis activity. Zinc metalloproteinases matched in fraction $\mathrm{C}$ were P-III metalloproteinase which contains metalloproteinase domain, disintegrin domain, and cysteine-rich domain (Gowda et al., 1994; Siigur et al., 2001; Siigur et al., 2004; Trummal et al., 2005; Takeda et al., 2007; Chen et al., 2008). Some of this kind of P-III metalloproteinase were confirmed that they can constitute complexes with C-type lectin homodimers light 
TABLE 2 | Toxins of NnTNV purification fraction D identified by LC-MS/MS analysis and Tox-Prot database.

\section{Peptide sequence}

LSPEEQQK

QLHLK

K.ILKGGLK.S

XIIGAPCRR

EEILR

RSEHEEQLMAK

TRTSWDEDIMLIR

QASQKWGR

LNPFR

SCAGMGQDCK

LDTVR

EFADK

\begin{tabular}{|c|c|}
\hline & C0JB73 \\
\hline & C0JB79 \\
\hline & C0JB71 \\
\hline & COJB77 \\
\hline & C0JB69 \\
\hline & C0JB85 \\
\hline & C0JB88 \\
\hline & C0JB84 \\
\hline & C0JB83 \\
\hline & C0JB87 \\
\hline & C0JB76 \\
\hline & C0JB86 \\
\hline & C0JB78 \\
\hline & C0JB82 \\
\hline & C0JB74 \\
\hline & C0JB81 \\
\hline & C0JB75 \\
\hline & C0JB72 \\
\hline \multirow[t]{3}{*}{ LTEALK } & COJB90 \\
\hline & C0JB89 \\
\hline & C0JB91 \\
\hline \multirow[t]{4}{*}{ KLDLR } & D2Y2H8 \\
\hline & D2Y2H6 \\
\hline & D2Y2C1 \\
\hline & D2Y2H7 \\
\hline \multirow[t]{2}{*}{ MIIFK } & G3LU44 \\
\hline & M5B4R7 \\
\hline IWDLK & H1ZZI8 \\
\hline TGVEIK & P01393 \\
\hline QITMNDLPVGR & P0CV91 \\
\hline ADLDLLR & PODME8 \\
\hline \multirow[t]{2}{*}{ EQITSRLK } & PODSJ8 \\
\hline & PODSJ9 \\
\hline GLPEDAK & PODUIO \\
\hline NEILK & P10736 \\
\hline \multirow[t]{3}{*}{ LEILK } & P81657 \\
\hline & PODMB9 \\
\hline & P86870 \\
\hline \multirow[t]{2}{*}{ LVPIASK } & P86538 \\
\hline & Q98956 \\
\hline ILGGIK & Q2XXP5 \\
\hline QEYGAERLR & Q3YEG6 \\
\hline \multirow[t]{5}{*}{ YENFNDFLK } & Q4VDB5 \\
\hline & P0CE80 \\
\hline & Q56JA9 \\
\hline & P0CE82 \\
\hline & P0CE81 \\
\hline LNLIR & Q5BLY5 \\
\hline KVHEVK & Q6T627 \\
\hline
\end{tabular}

Protein ID

Protein name

Reticulocalbin-2

Delta-pseudomyrmecitoxin-Pp1a subunit B

Kappa-stichotoxin-Shd1a/kappa-stichotoxin-Shd1b

U-scoloptoxin(21)-Sm2a

U-scoloptoxin(22)-Er1a

Thrombin-like enzyme ancrod

Snake venom metalloprotease inhibitor 02D01

Short cationic peptide-6a

Short cationic peptide-6b

U13-lycotoxin-Ls1f

U13-lycotoxin-Ls1b

U13-lycotoxin-Ls1f

Dermonecrotic toxin LarSicTox-alphall11 (Fragment)

Dermonecrotic toxin SaSicTox-betallB1bvi (Fragment)

Dermonecrotic toxin SaSicTox-betallB1biii (Fragment)

Dermonecrotic toxin SdSicTox-betallB1ai (Fragment)

Dermonecrotic toxin SdSicTox-betallB1bi (Fragment)

Dermonecrotic toxin SdSicTox-betallB1aii (Fragment)

Dermonecrotic toxin SpaSicTox-betallA2 (Fragment)

Dermonecrotic toxin SaSicTox-betallB1bxi (Fragment)

Dermonecrotic toxin SaSicTox-betallB1bxiv (Fragment)

Dermonecrotic toxin SaSicTox-betallB1bx (Fragment)

Dermonecrotic toxin SaSicTox-betallB1bix (Fragment)

Dermonecrotic toxin SaSicTox-betallB1bxiii (Fragment)

Dermonecrotic toxin SdSicTox-betallB1ai (Fragment)

Dermonecrotic toxin SdSicTox-betallB1bxii (Fragment)

Dermonecrotic toxin SaSicTox-betallB1aiii (Fragment)

Dermonecrotic toxin SaSicTox-betallB1bviii (Fragment)

Dermonecrotic toxin SaSicTox-betallB1biv (Fragment)

Dermonecrotic toxin SaSicTox-betallB1bvii (Fragment)

Dermonecrotic toxin SdSicTox-betallB1bv (Fragment)

Dermonecrotic toxin SaSicTox-betallB1bii (Fragment)

Dermonecrotic toxin SaSicTox-betallB2ii (Fragment)

Dermonecrotic toxin SaSicTox-betallB2i (Fragment)

Dermonecrotic toxin SaSicTox-betallB1 (Fragment)

U6-theraphotoxin-Hhn1a 4

U6-theraphotoxin-Hhn1a 2

U6-theraphotoxin-Hhn1a 1

U6-theraphotoxin-Hhn1a 3

Translationally controlled tumor protein homolog

Translationally controlled tumor protein homolog

Toxin Tpa7

Alpha-elapitoxin-Djk2a

Peroxiredoxin-4 (Fragments)

Peptide Hp1239

U-myrmeciitoxin(01)-Mg5a

U-myrmeciitoxin(01)-Mg5b

Beta-toxin Ct13

Venom allergen 5.01

Venom allergen 5

Venom allergen 5

Venom allergen 5

Cytotoxin $2 \mathrm{a}$

Cytotoxin $1 b$

Cysteine-rich venom protein TEL1 (Fragment)

Conotoxin LiC42

Dermonecrotic toxin LgSicTox-alphalA1

Dermonecrotic toxin LiSicTox-alphalA1a

Dermonecrotic toxin LsSicTox-alphalA1

Dermonecrotic toxin LiSicTox-alphalA1bii (Fragment)

Dermonecrotic toxin LiSicTox-alphalA1bi

Venom acid phosphatase Acph-1

L-amino-acid oxidase (Fragment)
Cover percent (\%)

4.25

21.2

32.14

7.25

8.15

5.56

2.60

25.00

26.32

8.33

8.33

8.33

1.82

1.82

1.82

1.82

1.82

1.82

1.82

1.83

1.83

1.82

1.82

1.82

1.82

1.82

1.83

1.82

1.82

1.82

1.82

1.82

2.19

2.19

2.19

5.15

5.15

5.15

5.15

2.91

2.89

6.10

8.33

30.56

10.45

13.56

13.56

8.64

2.20

2.48

2.48

2.22

11.67

8.64

2.86

11.69

3.21

2.94

3.21

2.98

2.94

1.29

10.00

(Continued on following page) 
TABLE 2 | (Continued) Toxins of NnTNV purification fraction D identified by LC-MS/MS analysis and Tox-Prot database.

Peptide sequence

\begin{tabular}{ll}
\hline GAEVIR & Q6XLL5 \\
GAEIIR & Q6XLL6 \\
TIEELAK & Q75WG7 \\
LENVEKEDGGPK & Q8JJ51 \\
LLNKR.S ! K.LLNKR & Q9BPF2 \\
& Q68IP5 \\
DILDK.S ! K.DLLDK & R4J7Z9 \\
& F8J2D3
\end{tabular}

\section{Protein name}

Potassium channel toxin alpha-KTx 6.10

Potassium channel toxin alpha-KTx 6.9

U13-hexatoxin-Mg1a

Snake venom metalloproteinase

Conotoxin Vn-05

Conotoxin mr5.4b (Fragment)

Hyaluronidase

Phospholipase-B 81
Cover percent (\%)

10.00
9.84
5.65
2.90
8.20
9.26
1.25
0.90

5.65

2.90

9.26

1.25

0.90

TABLE 3 | Proteins of NnTNV purification fraction C identified by LC-MS/MS analysis and N. nomurai genome database.

Peptide sequence

\section{A}

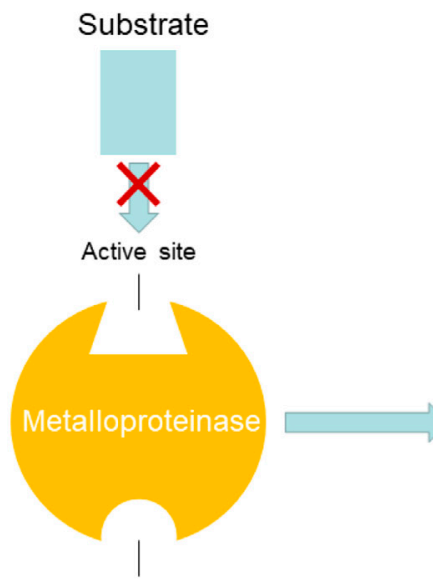

Subunit binding site

\section{Metalloproteinase}
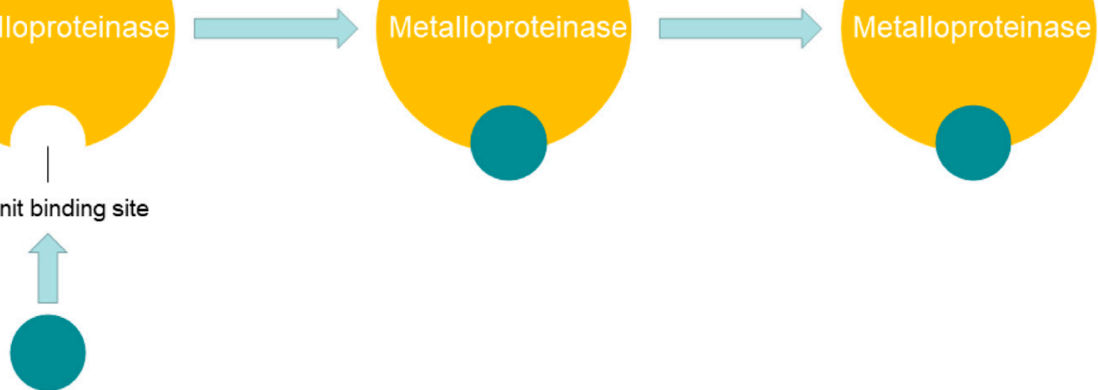

Regulatory subunit

B

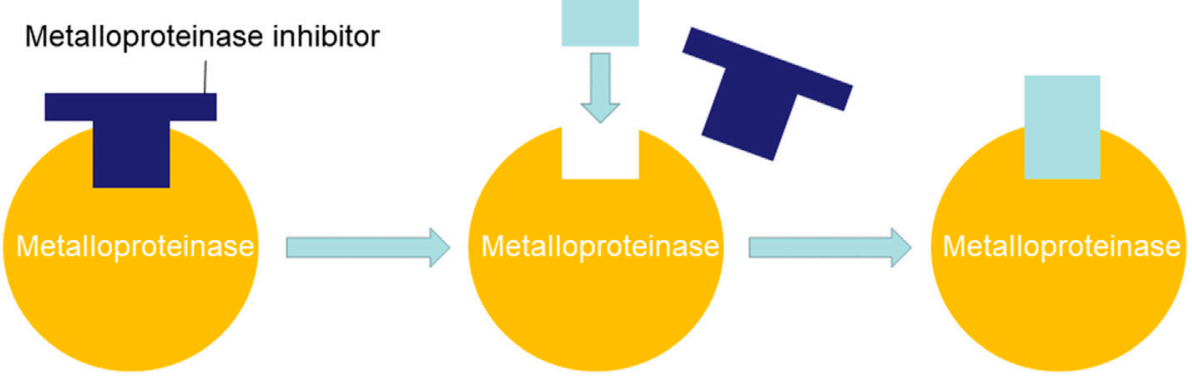

FIGURE 6 | Possible regulation mechanisms of NnVMP activity. (A) Metalloproteinase was activated by binding regulatory subunit. (B) Metalloproteinase was activated by disengaging inhibitor. 
TABLE 4 | The nucleotide sequence of 21 amino acids in Nemopilema nomurai.

\begin{tabular}{|c|c|c|}
\hline Amino acid & DNA sequence & mRNA sequence (codon) \\
\hline M & ATG/ATA & 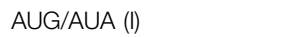 \\
\hline$P$ & CCT & $\mathrm{CCU}$ \\
\hline Q & CAA & CAA \\
\hline L & TTA/TG/CTA & UUA/UUG/CUA \\
\hline D & GAT & GAU \\
\hline 1 & АTT/ATA/ATC & AUU/AUA/AUC \\
\hline V & GTT/GTA/GTC & GUU/GUA/GUC \\
\hline $\mathrm{T}$ & ACAVACT & ACAVACU \\
\hline $\mathrm{F}$ & ТाT/TाC & UUU/UUC \\
\hline $\mathrm{N}$ & AAT/AAC & AAU/AAC \\
\hline Y & TAT/TAC & UAU/UAC \\
\hline W & TGA & UGA (termination codon) \\
\hline G & GGT/GGA & GGU/GGA \\
\hline \multirow[t]{2}{*}{$S$} & TCA/TCC/TCT/TCG/ & UCA/UCC/UCU/UCG/ \\
\hline & AGT/AGC & AGU/AGC \\
\hline K & AAA/AAG & AAA/AAG \\
\hline$E$ & GAA/GAG & GAA/GAG \\
\hline $\mathrm{R}$ & AGA & AGA \\
\hline $\mathrm{H}$ & CAT & CAU \\
\hline$A$ & GCT/GCA & GCU/GCA \\
\hline $\mathrm{T}$ & $\mathrm{ACA}$ & ACA \\
\hline C & TGT & UGU \\
\hline
\end{tabular}

chains, such as RVV-X (Gowda et al., 1994; Takeda et al., 2007) and CA-1 (Yamada et al., 1996). RVV-X is a P-III metalloproteinase complex isolated from Daboia siamensis (Eastern Russel's viper) which can activate coagulation factor X by cleavage of Arg-|-Xaa bonds (Gowda et al., 1994; Takeda et al., 2007). The heavy chain (Protein ID, Q7LZ61) was matched in fraction C. In RVV-X complex, the heavy chain is the catalytic subunit of activating coagulation factor $\mathrm{X}$, and the two light chains are regulatory subunits of binding the Gla domain of factor X (Takeya et al., 1992). Similar to RVV-X, this protein group can selectively hydrolyze factor $\mathrm{X}$ to $\mathrm{Xa}$, but some of them were also confirmed having azocasein hydrolysis activity such as the protein zinc metalloproteinase-disintegrin-like bothropasin from Bothrops jararaca (Mandelbaum et al., 1982). However, the zinc metalloproteinase-disintegrin-like atrase B isolated from Naja atra (Chinese cobra) did not show hydrolysis activity to fibrin, azocasein, and BAEE (Cherifi et al., 2010). Therefore, it was speculated that a zinc metalloproteinase which can hydrolyze azocasein was contained in fraction $\mathrm{C}$, and its activity could be activated by binding with regulatory subunits contained in fraction $D$. Differences from the C-type lectin subunits of RVV-X, the regulatory subunits in fraction $\mathrm{D}$, might affect the active center of the zinc metalloproteinase, similar to allosteric regulation. According to Table 2, fraction D might contain similar proteins to P-I SVMP and SVMP inhibitor. This indicated that there might have been an interaction between them that could inhibit the metalloproteinase activity. The inhibition of SVMP inhibitor may be disengaged by dilution or physiochemical change (Wagstaff et al., 2008).

To sum up the regulation mechanism, inactivated fractions $\mathrm{C}$ and $\mathrm{D}$ would recover the metalloproteinase activity by binding regulator or disaggregating inhibitor. Fraction $\mathrm{C}$ contained a zinc metalloproteinase which could hydrolysis azocasein under the activation of regulatory subunits in fraction D (Figure 6A). In another explanation, the interacted metalloproteinase and inhibitor in fraction $\mathrm{D}$ would disengage to activate metalloproteinase activity when fractions $C$ and $D$ were mixed (Figure 6B).

The spectra in $N$. nomurai genome database were also searched. The whole-genome database was uploaded to NCBI by Hak-Min Kim's team (Kim et al., 2019). LC-MS/MS analysis did not match any toxins in this database. BLAST of SVMP, which was matched in fractions $\mathrm{C}$ and $\mathrm{D}$, also had no significant similarity found. Although the nucleotide sequences of $N$. nomurai toxins were not obtained, some important peptide sequences were transformed into nucleotide sequence. The nucleotide sequence of 21 amino acids shown in Table 4 was obtained from the two N. nomurai mitochondrion proteins listed in Table 3. Through the comparison of the protein sequence and nucleotide sequence of ATP synthase F0 subunit 8 and $\mathrm{NADH}$ dehydrogenase subunit $4 \mathrm{~L}$ in $N$. nomurai, two interesting differences were found. In $N$. nomurai, the isoleucine (Ile, I) codon AUA would translate to methionine (Met, M), and the termination codon UGA would translate to tryptophan (Try, W). This should be paid special attention in further expression works. Based on this nucleotide sequence table, three peptides, which were matched to zinc metalloproteinase, SVMP, and SVMP inhibitor, were transformed into nucleotide sequence as shown in Figure 7. These sequences may provide references for further studies interested in NnVMP.

It has been a problem for a long time that jellyfish venom purification has been limited by the complex protein components. As shown in each purification step, different proteins may have similar physical properties and are hard to be completely isolated by chromatography. Low protein content also limit sample reloading of chromatography. As a new revealed property of $N$. nomurai toxins, the synergistic effect of proteinase activity may impact further activity-guided chromatography studies. Although jellyfish venom purification is difficult, it might reveal more venom properties in the purification process and provide references for further studies.

In conclusion, the toxic protease components from NnTNV were isolated by ammonium sulfate precipitation, DEAE Sepharose Fast Flow, and Superdex 75 column chromatography successively. After the three purification steps, the main proteinase activity was lost, but it could be recovered by mixing again. This is the first time that the synergistic effect of jellyfish proteinase activity has been revealed. Through LC-MS/MS analysis, it has been shown that the proteinase activity might have been contributed by metalloproteinases and regulated by metalloproteinase subunit or metalloproteinase inhibitor. Three important peptide sequences were transformed into nucleotide sequences to provide more information on $N$. nomurai metalloproteinases. The results could help further research in jellyfish toxins purification and expression. The synergistic effect might be a new entry point in purifying N. nomurai metalloproteinases and regulators. 

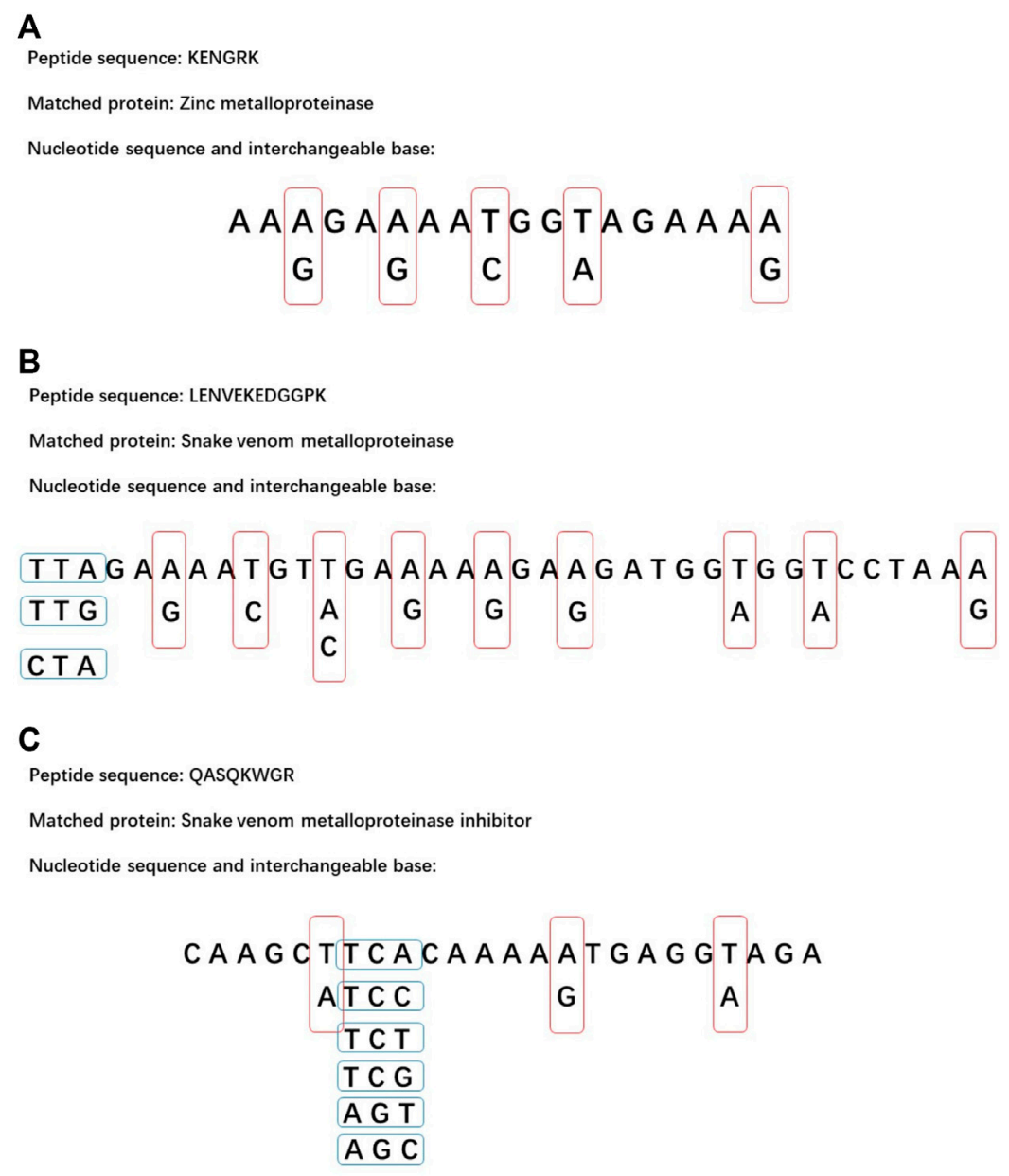

FIGURE 7 | Possible nucleotide sequence of three important peptides. The red and blue frames represent interchangeable bases. (A) The sequence of KENGRK. (B) The sequence of LENVEKEDGGPK. (C) The sequence of QASQKWGR.

\section{DATA AVAILABILITY STATEMENT}

The data sets presented in this study can be found in online repositories. The names of the repository/repositories and accession number(s) can be found below: ProteomeXchange with identifier PXD029333.

\section{ETHICS STATEMENT}

The animal study was reviewed and approved by the IOCAS Ethics Committee in March 2017, Ethics Application No. IOCAS/ KLEMB/20170301.

\section{AUTHOR CONTRIBUTIONS}

RL, XY, and CY performed the experiments. HY, PL, and CY designed the experiments and interpreted the data. HY and CY wrote the manuscript. All authors read and discussed the manuscript.

\section{FUNDING}

This work was supported by the National Key R\&D Program of China (2017YFE0111100-04, 2019YFC0312605), the National Natural Science Foundation of China (41776163, 41876164), and the Natural Science Foundation of Shandong Province (ZR2019QD012).

\section{SUPPLEMENTARY MATERIAL}

The Supplementary Material for this article can be found online at: https://www.frontiersin.org/articles/10.3389/fphar.2021.791847/ full\#supplementary-material 


\section{REFERENCES}

Ami, A., Oussedik-Oumehdi, H., and Laraba-Djebari, F. (2017). Biochemical and Biological Characterization of a Dermonecrotic Metalloproteinase Isolated from Cerastes Cerastes Snake Venom. J. Biochem. Mol. Toxicol. 31, 9. doi:10.1002/jbt.21835

Bernardes, C. P., Menaldo, D. L., Camacho, E., Rosa, J. C., Escalante, T., Rucavado, A., et al. (2013). Proteomic Analysis of Bothrops Pirajai Snake Venom and Characterization of BpirMP, a New P-I Metalloproteinase. J. Proteomics 80, 250-267. doi:10.1016/j.jprot.2013.01.021

Bloom, D. A., Burnett, J. W., and Alderslade, P. (1998). Partial Purification of Box Jellyfish (Chironex Fleckeri) Nematocyst Venom Isolated at the Beachside. Toxicon 36, 1075-1085. doi:10.1016/s0041-0101(98)00096-8

Cegolon, L., Heymann, W. C., Lange, J. H., and Mastrangelo, G. (2013). Jellyfish Stings and Their Management: A Review. Mar. Drugs 11, 523-550. doi:10.3390/ md11020523

Chen, H. S., Tsai, H. Y., Wang, Y. M., and Tsai, I. H. (2008). P-III Hemorrhagic Metalloproteinases from Russell's viper Venom: Cloning, Characterization, Phylogenetic and Functional Site Analyses. Biochimie 90, 1486-1498. doi:10.1016/j.biochi.2008.05.012

Chérifi, F., Rousselle, J. C., Namane, A., and Laraba-Djebari, F. (2010). CCSVMPase, a Novel Procoagulant Metalloproteinase from Cerastes Cerastes Venom: Purification, Biochemical Characterization and Protein Identification. Protein J. 29, 466-474. doi:10.1007/s10930-010-9273-1

Choo, Y. M., Lee, K. S., Yoon, H. J., Kim, B. Y., Sohn, M. R., Roh, J. Y., et al. (2010). Dual Function of a Bee Venom Serine Protease: Prophenoloxidase-Activating Factor in Arthropods and Fibrin(ogen)olytic Enzyme in Mammals. Plos One 5, e10393. doi:10.1371/journal.pone.0010393

Choo, Y. M., Lee, K. S., Yoon, H. J., Qiu, Y., Wan, H., Sohn, M. R., et al. (2012). Antifibrinolytic Role of a Bee Venom Serine Protease Inhibitor that Acts as a Plasmin Inhibitor. Plos One 7, e32269. doi:10.1371/journal.pone.0032269

Chung, J. J., Ratnapala, L. A., Cooke, I. M., and Yanagihara, A. A. (2001). Partial Purification and Characterization of a Hemolysin (CAH1) from Hawaiian Box Jellyfish (Carybdea Alata) Venom. Toxicon 39, 981-990. doi:10.1016/s00410101(00)00237-3

De Queiroz, M. R., Mamede, C. C. N., Fonseca, K. C., De Morais, N. C. G., De Sousa, B. B., Santos, N. A., et al. (2014). Rapid Purification of a New P-I Class Metalloproteinase from Bothrops Moojeni Venom with Antiplatelet Activity. Biomed. Res. Int. 2014, 12. doi:10.1155/2014/352420

Dekhil, H., Wisner, A., Marrakchi, N., El Ayeb, M., Bon, C., and Karoui, H. (2003). Molecular Cloning and Expression of a Functional Snake Venom Serine Proteinase, with Platelet Aggregating Activity, from the Cerastes Cerastes viper. Biochemistry 42, 10609-10618. doi:10.1021/bi034790b

Doley, R., and Kini, R. M. (2009). Protein Complexes in Snake Venom. Cell Mol Life Sci 66, 2851-2871. doi:10.1007/s00018-009-0050-2

Farsky, S. H., Gonçalves, L. R., Gutiérrez, J. M., Correa, A. P., Rucavado, A., Gasque, P., et al. (2000). Bothrops A Snake Venom and its Metalloproteinase BaP-1 Activate the Complement System. Role in Leucocyte RecruitmentRole in Leucocyte Recruitment. Mediators Inflamm. 9, 213-221. doi:10.1080/ 09629350020025728

Fox, J. W., and Serrano, S. M. (2005). Structural Considerations of the Snake Venom Metalloproteinases, Key Members of the M12 Reprolysin Family of Metalloproteinases. Toxicon 45, 969-985. doi:10.1016/j.toxicon.2005.02.012

Fox, J. W., and Serrano, S. M. (2008). Insights into and Speculations about Snake Venom Metalloproteinase (SVMP) Synthesis, Folding and Disulfide Bond Formation and Their Contribution to Venom Complexity. FEBS J. 275, 3016-3030. doi:10.1111/j.1742-4658.2008.06466.x

Gowda, D. C., Jackson, C. M., Hensley, P., and Davidson, E. A. (1994). Factor X-Activating Glycoprotein of Russell's viper Venom. Polypeptide Composition and Characterization of the Carbohydrate Moieties. J. Biol. Chem. 269, 10644-10650. doi:10.1016/s0021-9258(17)34108-x

Gutiérrez, J., Romero, M., Díaz, C., Borkow, G., and Ovadia, M. (1995). Isolation and Characterization of a Metalloproteinase with Weak Hemorrhagic Activity from the Venom of the Snake Bothrops asper (Terciopelo). Toxicon 33, 19-29. doi:10.1016/0041-0101(94)00138-x

Helmholz, H., Naatz, S., Lassen, S., and Prange, A. (2008). Isolation of a Cytotoxic Glycoprotein from the Scyphozoa Cyanea Lamarckii by Lectin-Affinity
Chromatography and Characterization of Molecule Interactions by Surface Plasmon Resonance. J. Chromatogr. B Analyt Technol. Biomed. Life Sci. 871, 60-66. doi:10.1016/j.jchromb.2008.06.040

Horiike, T., Nagai, H., and Kitani, S. (2015). Identification of Allergens in the Box Jellyfish Chironex Yamaguchii that Cause Sting Dermatitis. Int. Arch. Allergy Immunol. 167, 73-82. doi:10.1159/000434721

Howes, J. M., Wilkinson, M. C., Theakston, R. D., and Laing, G. D. (2003). The Purification and Partial Characterisation of Two Novel Metalloproteinases from the Venom of the West African Carpet viper, Echis Ocellatus. Toxicon 42, 21-27. doi:10.1016/s0041-0101(03)00096-5

Jungo, F., and Bairoch, A. (2005). Tox-Prot, the Toxin Protein Annotation Program of the Swiss-Prot Protein Knowledgebase. Toxicon 45, 293-301. doi:10.1016/j.toxicon.2004.10.018

Kawahara, M., Uye, S., Ohtsu, K., and Iizumi, H. (2006). Unusual Population Explosion of the Giant Jellyfish Nemopilema Nomurai (Scyphozoa: Rhizostomeae) in East Asian Waters. Mar. Ecol. Prog. Ser. 307, 161-173. doi:10.3354/meps307161

Kim, H. M., Weber, J. A., Lee, N., Park, S. G., Cho, Y. S., Bhak, Y., et al. (2019). The Genome of the Giant Nomura's Jellyfish Sheds Light on the Early Evolution of Active Predation. BMC Biol. 17, 28. doi:10.1186/s12915-019-0643-7

Laemmli, U. K. (1970). Cleavage of Structural Proteins during the Assembly of the Head of Bacteriophage T4. Nature 227, 680, 5.doi:10.1038/227680a0

Lassen, S., Helmholz, H., Ruhnau, C., and Prange, A. (2011). A Novel Proteinaceous Cytotoxin from the Northern Scyphozoa Cyanea Capillata (L.) with Structural Homology to Cubozoan Haemolysins. Toxicon 57, 721-729. doi:10.1016/j.toxicon.2011.02.004

Lassen, S., Wiebring, A., Helmholz, H., Ruhnau, C., and Prange, A. (2012). Isolation of a Nav Channel Blocking Polypeptide from Cyanea Capillata Medusae - a Neurotoxin Contained in Fishing Tentacle Isorhizas. Toxicon 59, 610-616. doi:10.1016/ j.toxicon.2012.02.004

Lauridsen, L. P., Laustsen, A. H., Lomonte, B., and Gutiérrez, J. M. (2016). Toxicovenomics and Antivenom Profiling of the Eastern green Mamba Snake (Dendroaspis Angusticeps). J. Proteomics 136, 248-261. doi:10.1016/ j.jprot.2016.02.003

Lee, H., Jung, E. S., Kang, C., Yoon, W. D., Kim, J. S., and Kim, E. (2011). Scyphozoan Jellyfish Venom Metalloproteinases and Their Role in the Cytotoxicity. Toxicon 58, 277-284. doi:10.1016/j.toxicon.2011.06.007

Li, R., Yu, H., Feng, J., Xing, R., Liu, S., Wang, L., et al. (2011). Two-Step Purification and In Vitro Characterization of a Hemolysin from the Venom of Jellyfish Cyanea Nozakii Kishinouye. Int. J. Biol. Macromol 49, 14-19. doi:10.1016/j.ijbiomac.2011.03.005

Li, R., Yu, H., Xing, R., Liu, S., Qing, Y., Li, K., et al. (2012). Isolation, Identification and Characterization of a Novel Antioxidant Protein from the Nematocyst of the Jellyfish Stomolophus meleagris. Int. J. Biol. Macromol 51, 274-278. doi:10.1016/j.ijbiomac.2012.05.015

Li, R., Yu, H., Xing, R., Liu, S., Qing, Y., Li, K., et al. (2013). Isolation and In Vitro Partial Characterization of Hemolytic Proteins from the Nematocyst Venom of the Jellyfish Stomolophus meleagris. Toxicol. Vitro 27, 1620-1625. doi:10.1016/ j.tiv.2013.04.004

Li, R., Yu, H., Xue, W., Yue, Y., Liu, S., Xing, R., et al. (2014). Jellyfish Venomics and Venom Gland Transcriptomics Analysis of Stomolophus meleagris to Reveal the Toxins Associated with Sting. J. Proteomics 106, 17-29. doi:10.1016/ j.jprot.2014.04.011

Li, R., Yu, H., Yue, Y., and Li, P. (2018). Combined Proteome and Toxicology Approach Reveals the Lethality of Venom Toxins from Jellyfish Cyanea Nozakii. J. Proteome Res. 17, 3904-3913. doi:10.1021/acs.jproteome.8b00568

Li, A., Yu, H., Li, R., Liu, S., Xing, R., and Li, P. (2019). Inhibitory Effect of Metalloproteinase Inhibitors on Skin Cell Inflammation Induced by Jellyfish Nemopilema Nomurai Nematocyst Venom. Toxins (Basel) 11, 12. doi:10.3390/ toxins 11030156

Li, R., Yu, H., Li, T., and Li, P. (2020). Comprehensive Proteome Reveals the Key Lethal Toxins in the Venom of Jellyfish Nemopilema Nomurai. J. Proteome Res. 19, 2491-2500. doi:10.1021/acs.jproteome.0c00277

Liumin, M., Ling-bo, L., Jian-zhong, L., and Jiansheng, C. J. (2011). Taxonomic Relationship between Nemopilema Nomurai(in the Yellow Sea of China and the East China Sea)and Stomolophus meleagris Based on the Analysis of 18 SrDNA Partial Sequences. Mar. Fish. 33, 131-137.

Mandelbaum, F. R., Reichel, A. P., and Assakura, M. T. (1982). Isolation and Characterization of a Proteolytic Enzyme from the Venom of the Snake 
Bothrops jararaca (Jararaca). Toxicon 20, 955-972. doi:10.1016/0041-0101(82) 90098-8

Marrakchi, N., Zingali, R. B., Karoui, H., Bon, C., and el Ayeb, M. (1995). Cerastocytin, A New Thrombin-Like Platelet Activator from the Venom of the Tunisian Viper Cerastes Cerastes. Biochim. Biophys. Acta 1244, 147-156. doi:10.1016/0304-4165(94)00216-k

Marrakchi, N., Barbouche, R., Guermazi, S., Bon, C., and el Ayeb, M. (1997). Procoagulant and Platelet-Aggregating Properties of Cerastocytin from Cerastes Cerastes Venom. Toxicon 35, 261-272. doi:10.1016/s0041-0101(96)00116-x

Morine, N., Matsuda, S., Terada, K., Eto, A., Ishida, I., and Oku, H. (2008). Neutralization of Hemorrhagic Snake Venom Metalloproteinase HR1a from Protobothrops Flavoviridis by Human Monoclonal Antibody. Toxicon 51, 345-352. doi:10.1016/j.toxicon.2007.10.009

Patiño, A. C., Pereañez, J. A., Núñez, V., Benjumea, D. M., Fernandez, M., Rucavado, A., et al. (2010). Isolation and Biological Characterization of Batx-I, a Weak Hemorrhagic and Fibrinogenolytic PI Metalloproteinase from Colombian Bothrops A Venom. Toxicon 56, 936-943. doi:10.1016/j.toxicon.2010.06.016

Rastogi, A., Sarkar, A., and Chakrabarty, D. (2017). Partial Purification and Identification of a Metalloproteinase with Anticoagulant Activity from Rhizostoma Pulmo (Barrel Jellyfish). Toxicon 132, 29-39. doi:10.1016/j.toxicon.2017.04.006

Rottini, G., Gusmani, L., Parovel, E., Avian, M., and Patriarca, P. (1995). Purification and Properties of a Cytolytic Toxin in Venom of the Jellyfish Carybdea Marsupialis. Toxicon 33, 315-326. doi:10.1016/0041-0101(94)00174-7

Sánchez-Rodríguez, J., Torrens, E., and Segura-Puertas, L. (2006). Partial Purification and Characterization of a Novel Neurotoxin and Three Cytolysins from Box Jellyfish (Carybdea Marsupialis) Nematocyst Venom. Arch. Toxicol. 80, 163-168. doi:10.1007/s00204-005-0023-7

Siigur, E., Tõnismägi, K., Trummal, K., Samel, M., Vija, H., Subbi, J., et al. (2001). Factor X Activator from Vipera Lebetina Snake Venom, Molecular Characterization and Substrate Specificity. Biochim. Biophys. Acta 1568, 90-98. doi:10.1016/s0304-4165(01)00206-9

Siigur, E., Aaspõllu, A., Trummal, K., Tõnismägi, K., Tammiste, I., Kalkkinen, N., et al. (2004). Factor X Activator from Vipera Lebetina Venom Is Synthesized from Different Genes. Biochim. Biophys. Acta 1702, 41-51. doi:10.1016/ j.bbapap.2004.07.007

Sun, Q. Y., and Bao, J. (2010). Purification, Cloning and Characterization of a Metalloproteinase from Naja Atra Venom. Toxicon 56, 1459-1469. doi:10.1016/j.toxicon.2010.08.013

Sun, S., Sun, X.-X., and Jenkinson, I. R. (2015a). Preface: Giant Jellyfish Blooms in Chinese Waters. Hydrobiologia 754, 1-11. doi:10.1007/s10750-015-2320-3

Sun, S., Zhang, F., Li, C., Wang, S., Wang, M., Tao, Z., et al. (2015b). Breeding Places, Population Dynamics, and Distribution of the Giant Jellyfish Nemopilema Nomurai (Scyphozoa: Rhizostomeae) in the Yellow Sea and the East China Sea. Hydrobiologia 754, 59-74. doi:10.1007/s10750-015-2266-5

Takeda, S., Igarashi, T., and Mori, H. (2007). Crystal Structure of RVV-X: An Example of Evolutionary Gain of Specificity by ADAM Proteinases. FEBS Lett. 581, 5859-5864. doi:10.1016/j.febslet.2007.11.062

Takeya, H., Nishida, S., Miyata, T., Kawada, S., Saisaka, Y., Morita, T., et al. (1992). Coagulation Factor X Activating Enzyme from Russell's viper Venom (RVVX). A Novel Metalloproteinase with Disintegrin (Platelet Aggregation Inhibitor)-like and C-type Lectin-like Domains. J. Biol. Chem. 267, 14109-14117. doi:10.1016/s0021-9258(19)49685-3

Trummal, K., Tõnismägi, K., Siigur, E., Aaspõllu, A., Lopp, A., Sillat, T., et al. (2005). A Novel Metalloprotease from Vipera Lebetina Venom Induces Human Endothelial Cell Apoptosis. Toxicon 46, 46-61. doi:10.1016/j.toxicon.2005.03.008

Wagstaff, S. C., Favreau, P., Cheneval, O., Laing, G. D., Wilkinson, M. C., Miller, R. L., et al. (2008). Molecular Characterisation of Endogenous Snake Venom Metalloproteinase Inhibitors. Biochem. Biophys. Res. Commun. 365, 650-656. doi:10.1016/j.bbrc.2007.11.027

Wang, W. J., Shih, C. H., and Huang, T. F. (2004). A Novel P-I Class Metalloproteinase with Broad Substrate-Cleaving Activity, Agkislysin, from Agkistrodon Acutus Venom. Biochem. Biophys. Res. Commun. 324, 224-230. doi:10.1016/j.bbrc.2004.09.031

Xiao, L., Liu, S., He, Q., Wang, Q., Ye, X., Liu, G., et al. (2011). The Acute Toxicity and Hematological Characterization of the Effects of Tentacle-Only Extract from the Jellyfish Cyanea Capillata. Mar. Drugs 9, 526-534. doi:10.3390/md9040526

Xiong, S., and Huang, C. (2018). Synergistic Strategies of Predominant Toxins in Snake Venoms. Toxicol. Lett. 287, 142-154. doi:10.1016/j.toxlet.2018.02.004
Xiong, S., Luo, Y., Zhong, L., Xiao, H., Pan, H., Liao, K., et al. (2017). Investigation of the Inhibitory Potential of Phospholipase A2 Inhibitor Gamma from Sinonatrix $A$ to Snake Envenomation. Toxicon 137, 83-91. doi:10.1016/ j.toxicon.2017.07.019

Xu, L. P., Jiang, W. J., Ma, T., Qiu, P. X., Hou, J., Huang, Y. J., et al. (2006). Expression, Purification and Molecular Modeling of Recombinant Fibrinogenase [IV], a Metalloproteinase from Deinakistrodon Acutus Venom. Toxicon 47, 241-248. doi:10.1016/j.toxicon.2005.11.005

Xu, Y., Ishizaka, J., Yamaguchi, H., Siswanto, E., and Wang, S. (2013). Relationships of Interannual Variability in SST and Phytoplankton Blooms with Giant Jellyfish (Nemopilema Nomurai) Outbreaks in the Yellow Sea and East China Sea. J. Oceanogr 69, 511-526. doi:10.1007/s10872-013-0189-1

Yamada, D., Sekiya, F., and Morita, T. (1996). Isolation and Characterization of Carinactivase, a Novel Prothrombin Activator in Echis carinatus Venom with a Unique Catalytic Mechanism. J. Biol. Chem. 271, 5200-5207. doi:10.1074/ jbc.271.9.5200

Yang, Y., Cun, S., Peng, L., Xie, X., Wei, J., Yang, W., et al. (2003). cDNA Cloning, Identification and Characterization of a Novel Cystatin from the Tentacle of Cyanea Capillata. Biochimie 85, 1033-1039. doi:10.1016/s0300-9084(03)00132-9

Yang, S., Yang, F., Zhang, B., Lee, B. H., Li, B., Luo, L., et al. (2017). A Bimodal Activation Mechanism Underlies Scorpion Toxin-Induced Pain. Sci. Adv. 3, e1700810. doi:10.1126/sciadv. 1700810

Yoon, W. D., Lee, H. E., Han, C., Chang, S.-J., and Lee, K. (2014). Abundance and Distribution of Nemopilema Nomurai (Scyphozoa, Rhizostomeae), in Korean Waters in 2005-2013. Ocean Sci. J. 49, 183-192. doi:10.1007/s12601-014-0018-5

Yu, H., Liu, X., Dong, X., Li, C., Xing, R., Liu, S., et al. (2005). Insecticidal Activity of Proteinous Venom from Tentacle of Jellyfish Rhopilema Esculentum Kishinouye. Bioorg. Med. Chem. Lett. 15, 4949-4952. doi:10.1016/j.bmcl.2005.08.015

Yue, Y., Yu, H., Li, R., Xing, R., Liu, S., Li, K., et al. (2017a). Functional Elucidation of Nemopilema Nomurai and Cyanea Nozakii Nematocyst Venoms' Lytic Activity Using Mass Spectrometry and Zymography. Toxins (Basel) 9, 18. doi:10.3390/toxins 9020047

Yue, Y., Yu, H., Li, R., Xing, R., Liu, S., Li, K., et al. (2017b). Biochemical and Kinetic Evaluation of the Enzymatic Toxins from Two Stinging Scyphozoans Nemopilema Nomurai and Cyanea Nozakii. Toxicon 125, 1-12. doi:10.1016/ j.toxicon.2016.11.005

Yue, Y., Yu, H., Li, R., and Li, P. (2021). Topical Exposure to Nemopilema Nomurai Venom Triggers Oedematogenic Effects: Enzymatic Contribution and Identification of Venom Metalloproteinase. Toxins (Basel) 13, 44. doi:10.3390/toxins13010044

Zhang, M., Fishman, Y., Sher, D., and Zlotkin, E. (2003). Hydralysin, a Novel Animal Group-Selective Paralytic and Cytolytic Protein from a Noncnidocystic Origin in hydra. Biochemistry 42, 8939-8944. doi:10.1021/bi0343929

Zhang, S. T., Lu, P., Qin, Y. F., Chen, S. J., and Guo, A. G. (2010). Cloning and Identification of a Novel P-II Class Snake Venom Metalloproteinase from Gloydius Halys. Appl. Biochem. Biotechnol. 162, 1391-1402. doi:10.1007/ s12010-010-8911-6

Zhu, L., Yuan, C., Chen, Z., Wang, W., and Huang, M. (2010). Expression, Purification and Characterization of Recombinant Jerdonitin, a P-II Class Snake Venom Metalloproteinase Comprising Metalloproteinase and Disintegrin Domains. Toxicon 55, 375-380. doi:10.1016/j.toxicon.2009.08.016

Conflict of Interest: The authors declare that the research was conducted in the absence of any commercial or financial relationships that could be construed as a potential conflict of interest.

Publisher's Note: All claims expressed in this article are solely those of the authors and do not necessarily represent those of their affiliated organizations or those of the publisher, the editors, and the reviewers. Any product that may be evaluated in this article, or claim that may be made by its manufacturer, is not guaranteed or endorsed by the publisher.

Copyright (c) $2021 \mathrm{Yu}, \mathrm{Li}$, Yin, Yu and Li. This is an open-access article distributed under the terms of the Creative Commons Attribution License (CC BY). The use, distribution or reproduction in other forums is permitted, provided the original author(s) and the copyright owner(s) are credited and that the original publication in this journal is cited, in accordance with accepted academic practice. No use, distribution or reproduction is permitted which does not comply with these terms. 